\title{
Research on Multifunctional Suspension Controller Based on Bidirectional Buck-Boost Circuit
}

\section{Xing Chen ( $\nabla$ bit_cx@163.com )}

Chongqing University of Arts and Sciences

\section{Sen Han}

Chongqing Jiaotong University

\section{Tian Hong Luo}

Chongqing University of Arts and Sciences

\section{Dan Peng}

Chongqing Jiaotong University

\section{Shui Li Zheng}

Chongqing Jiaotong University

\section{Original Article}

Keywords: Electromagnetic suspension , Bidirectional DC-DC converter , Active suspension , Energy regeneration, Hybrid model , Fuzzy PID controller

Posted Date: November 18th, 2020

DOI: https://doi.org/10.21203/rs.3.rs-109622/v1

License: (c) (1) This work is licensed under a Creative Commons Attribution 4.0 International License.

Read Full License 


\section{Title page}

\section{Research on Multifunctional Suspension Controller Based on Bidirectional Buck-Boost Circuit}

Xing Chen, born in 1985, is currently an associate professor at Chongqing University of Arts and Sciences, China. He received his PhD degree from Beijing Institute of Technology, China, in 2015. His research interests include vehicle dynamics and control, transmission technology and theory.

E-mail: bit_cx@163.com

Sen Han, born in 1995, is currently a master candidate at School of Mechatronics \& Vehicle Engineer, Chongqing Jiaotong University, China.

Tian-Hong Luo, born in 1975, is currently a professor at Chongqing University of Arts and Sciences, China. He received his PhD degree from Chongqing University, China, in 2005. His research interests include mechanical dynamics and control, transmission technology and theory.

Dan Peng, born in 1997, is currently a master candidate at School of Mechatronics \& Vehicle Engineer, Chongqing Jiaotong University, China.

Shui-Li Zheng, born in 1996, is currently a master candidate at School of Mechatronics \& Vehicle Engineer, Chongqing Jiaotong University, China.

\section{Corresponding author: Xing Chen E-mail: bit_cx@163.com}




\title{
Research on Multifunctional Suspension Controller Based on Bidirectional Buck- Boost Circuit
}

\author{
Xing Chen ${ }^{1}{ }^{2}$ • Sen Han $^{3} \cdot$ Tian-Hong Luo ${ }^{1}$ - Dan Peng ${ }^{3}$ Hui-Li Zheng ${ }^{3}$
}

(C) Chinese Mechanical Engineering Society and Springer-Verlag Berlin Heidelberg

\begin{abstract}
As is known, the active suspensions have high energy consumption problems, while energy-regenerative suspensions have limited performance in improving vibration effects. In order to make up for the contradiction between the dynamic performance of the suspension and the energy consumption, this paper uses a linear motor with a bidirectional Buck-Boost circuit to design a multifunctional controller. On this basis, Energy-Consuming Active Control (ECAC) and Regenerative Semi-Active Control (RSAC) strategies are proposed. They make full use of the motor's characteristics in different working areas and improve the scope of application of the suspension. Besides, to ensure that the motor current can accurately track the target value, the inner loop controller uses fuzzy PID to achieve it, which improves the controller's adaptability and reduces the need for the mathematical model of the control object. The simulation results show that the proposed control circuit can achieve the required control effect. Under the active control strategy, the ride comfort of the vehicle is improved by about $27 \%$, and other performances are also controlled within an appropriate range. In the energy-regenerative mode, not only is the energy recovered, but the vehicle ride comfort is also improved by about $10 \%$. Compared with the traditional single-performance suspension, the proposed suspension system improves the suspension's overall performance and satisfies different driving conditions and driver needs.
\end{abstract}

Keywords: Electromagnetic suspension - Bidirectional DC-DC converter $\bullet$ Active suspension $\bullet$ Energy regeneration $\bullet$ Hybrid model - Fuzzy PID controller

\section{Introduction}

The role of the suspension system is to attenuate vibrations

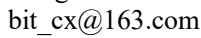

$\triangle$ Xing Chen University of Arts and Sciences, Chongqing 402160, China
}

and impact caused by random road excitation, which determines the ride comfort and road handling of the vehicle. Among them, active suspension performance is particularly outstanding. At present, the control technology of active suspension has made significant development, such as adaptive control [1], robust control [2-3], and intelligent control [4], which can solve different control goals. Although the active suspension system is currently ideal, the problem of high energy consumption restricts its application [5]. According to the literature [6-9], the traditional vehicle suspension system has a well recovery potential. If the energy is harvested and reused, the vehicle's fuel consumption and exhaust emissions will be further reduced. Therefore, when designing a suspension controller, it is necessary to consider the damping performance and energy consumption.

Researchers have conducted much research on the recovery technology of suspension vibration energy, and different energy recovery suspension systems have their advantages and disadvantages [10]. Electromagnetic energy-harvesting shock absorbers are popular in various vibration energy recovery structures. Because they have high energy conversion efficiency, fast response speed, strong controllability, and superior energy recovery capabilities. The generator type is mainly divided into linear motor [11-14] and rotary motor [15-17]. The rotating electric machine has been developed rapidly because of its higher recovery efficiency and average power characteristics. But it is necessary to design an additional mechanical conversion structure to convert the reciprocating motion into a rotary motion. Li, Zhang and

2 State Key Laboratory of Mechanical Transmission, Chongqing University, Chongqing 400044, China

School of Mechatronics \& Vehicle Engineer, Chongqing Jiaotong University, Chongqing 400074, China 
Guo et al. [18-20] established an energy-harvesting shock absorber that combines a rotating electric machine and a rack and pinion mechanism. Simultaneously, a motion rectifier (MMR) is used to complete the direction conversion, which improves recovery efficiency. Then the shock absorber realizes adjustable damping by controlling the size of the electric load. Another structure is to use a ball screw and a rotating motor to form an energy-regenerative damping mechanism. Chen et al. [21] proposed adjusting the electromagnetic force to fit the ideal control force by changing the number of rechargeable batteries. The semiactive suspension's recovery efficiency is as high as $77.72 \%$, guaranteeing the damping effect. Besides, Xie et al. [22] designed an energy regenerative shock absorber composed of multiple controlled generators, where each power generation mechanism consists of two rotating electric machines and a ball screw mechanism. The damping coefficient is changing by controlling the number of generators used and adjusting the external adjustable resistance. Also, linear motors have been widely used because of their simple structure and fast response speed, and no mechanical transmission loss. Shi et al. [23] combined a DC linear motor and a three-stage adjustable shock absorber in parallel and discussed the influence of adjustable damping value on recovered power. At the same time, Shi et al. [24] also used a one-way Buck-Boost circuit to design as an energy-regenerative controller. By outputting a set of PWM signals to control the circuit is on and off, the motor current was controlled to increase the control bandwidth of semi-active control.

However, the above energy-regenerative suspension also has shortcomings. First of all, the active electromagnetic suspension that combines a ball screw/rack or rack/pinion mechanism with a rotating motor has the following drawbacks: $\square$ Due to the addition of a mechanical conversion mechanism, the complexity of the system is increased; $\square$ The service life of the ball screw or rack/pinion mechanism is short and requires regular maintenance; $\square$ There are gaps and inertial mass, the system responds slowly; then, there are deficiencies in the structural design, and the control methods generally belong to the semi-active energy-regenerative control strategy. Compared with the energy-consuming active control, vehicle performance cannot be further improved. Simultaneously, the operating mode is single, which cannot meet the complex working conditions and different driving requirements.

In response to these problems, this paper designs a bidirectional Buck-Boost transformer circuit controller, which uses the same electromechanical infrastructure to achieve energy consumption control and energy recovery. By changing the controller's power switch, suspension control and mode switching can be realized. Different control strategies are designed on this basis, and the performance and recovery efficiency of the shock absorber under different driving conditions are analyzed. The designed controller combines the advantages of energy regeneration and active control to meet different driving conditions and performance requirements. If appropriate switching conditions are selected, the suspension can realize energy self-supply.

\section{System scheme design}

\subsection{Working principle of suspension system}

In order to realize the energy recovery control and energy consumption control, the actuator adopts a linear motor structure, and the overall structure of the shock absorber is shown in Figure 1. Regardless of the mode, the control force is determined by the motor current's size which is adjusted by the duty cycle. The value of the control force is calculated by the control strategy and the sensor input signal, and then the duty cycle value is output by the current controller. To reduce the error between the actual and ideal current, the current controller composed of a fuzzy PID control algorithm is selected, which has higher accuracy and rapidity. Then, the PWM generator outputs the PWM wave to control the Buck-Boost Circuit. In the energy regenerative mode, the linear motor converts the vertical vibration's kinetic energy caused by the uneven road into electrical energy. It then inputs the electrical energy into the energy storage element through a full-bridge rectifier and a DC transformer. In the energy consumption control mode, the electric energy in the energy storage element is used to obtain the required control voltage value through the BuckBoost Circuit, and the rectifier controls the direction of the voltage. The linear motor uses the input voltage to generate the corresponding control force to reduce the road's vibration. 


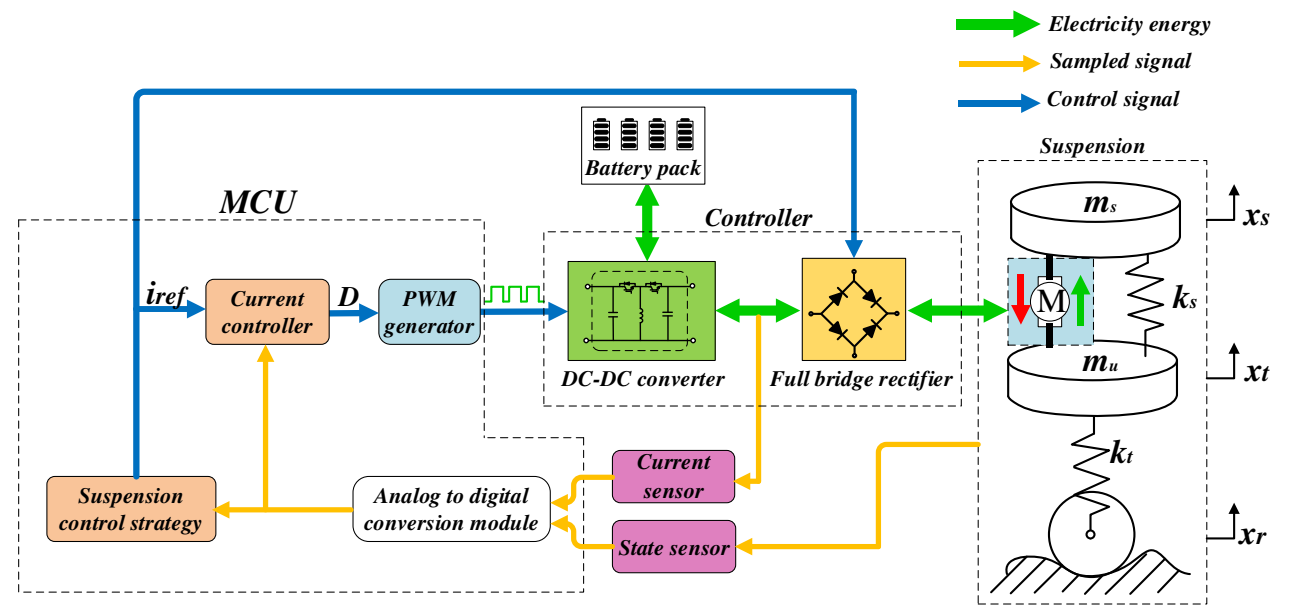

Figure 1 Topology of the multifunctional suspension system

\subsection{Controller circuit design}

The topological structure of the controller circuit is shown in Figure 2. The linear motor can be regarded as an adjustable voltage source $E$ plus a resistor $R_{m}$ and an inductance $L_{m}$. The motor generates an induced electromotive force $E$ under the relative motion, which is expressed as follows.

$$
E=K_{v} \cdot v
$$

Where $v$ represents the relative speed between the body and the tire, and $K_{v}$ represents the induced back electromotive force coefficient. However, current $i_{1}$ determines the electromagnetic force $f_{e}$ generated by the motor, and its magnitude is:

$$
f_{e}=K_{i} \cdot i_{1}
$$

Then, the switches of $S_{I} \sim S_{4}$ form a full-wave rectifier, which converts voltages in different directions into unidirectional voltages for voltage conversion. Capacitors $C_{1}$ and $C_{2}$ are filter capacitors (filtering, energy storage, and voltage stabilization) at the input and output, respectively, which reduce the voltage fluctuations and avoid the spike voltage from damaging the circuit components. $S_{5}$ and $S_{6}$ are a pair of complementary switches that receive PWM control signals, and their on-off controls the current and voltage of the circuit and controls the switching of the input and output directions. The inductance $L$ is the most critical part of the entire circuit and is the input and output energy carrier. It cooperates with the switches $S_{5}$ and $S_{6}$ to realize the bidirectional Buck-Boost conversion. The switch $S_{7}$ avoids the power supply energy flowing into the circuit to consume energy during the energy regenerative control. And the energy storage system can be regarded as a model of a fixed voltage source and a resistor in series.

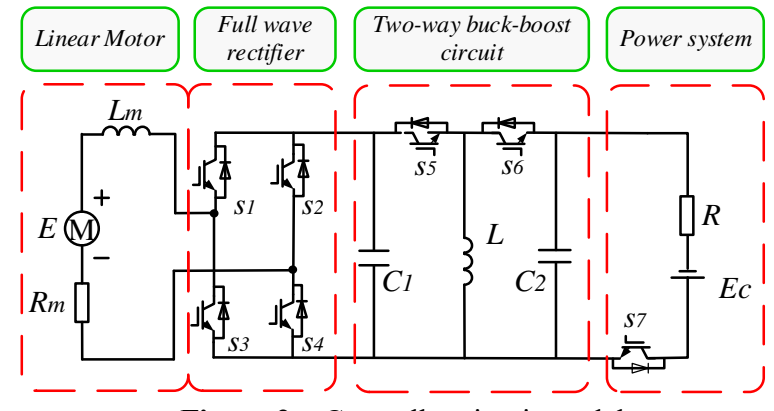

Figure 2 Controller circuit model

\section{Modelling and analysis}

\subsection{Suspension Model}

Since the simplified $1 / 4$ vehicle model can fully reflect the vertical vibration caused by external disturbances and can obtain the corresponding parameter response in time, the research object selects a suspension model with two degrees of freedom, as shown in Figure 3. Moreover, the road input uses filtered white noise [25].

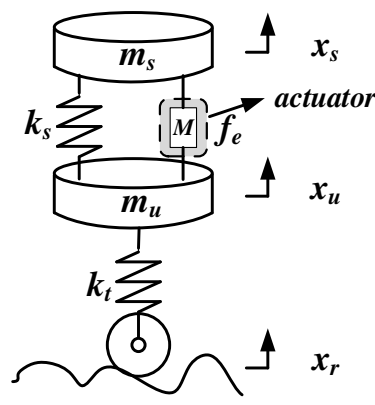

Figure 3 Quarter vehicle model

According to the model, the dynamic equation can be expressed as: 


$$
\begin{aligned}
& m_{s}=-k_{s}\left(x_{s}-x_{u}\right)+f_{e} \\
& m_{u}=k_{s}\left(x_{s}-x_{u}\right)-f_{e}-k_{t}\left(x_{u}-x_{r}\right)
\end{aligned}
$$

Where $m_{s}$ and $m_{u}$ represent the sprung mass and unsprung mass respectively; $k_{s}$ and $k_{t}$ are the suspension stiffness and tire stiffness respectively; the vertical displacements of the sprung mass and unsprung masse are defined as $x_{s}$ and $x_{u} ; f_{e}$ is the force generated by the linear motor, including damping force (energy regeneration mode) and control force (active control mode); $x_{r}$ is the displacement of the road disturbance, and it is expressed as follows:

$$
\stackrel{\&}{\&}=-2 \pi f_{0} x_{r}+2 \pi n_{0} \sqrt{G_{q}\left(n_{0}\right) v} \cdot w
$$

Where $n_{0}$ is the reference spatial frequency; $f_{0}$ is the lower cut-off frequency; $v$ is the vehicle speed; $w$ is the White Gaussian Noise with an average value of zero; $G_{q}\left(n_{0}\right)$ is the road irregularity coefficient.

\subsection{Circuit state analysis}

Since the control circuit will work in different operating states, so it is necessary to study the energy flow of the control circuit carefully to grasp its control performance. It is worth noting that the switching period $T$ is usually tiny, and the back electromotive force $E$ is viewed as unchanged. The suspension working mode is switched by the full-bridge rectifier and switches $S_{5}$ and $S_{6}$.

\subsubsection{Energy recovery mode}

When the shock absorber is in the energy recovery state, the equivalent damping size of the shock absorber is determined by the duty cycle of $S_{5}$ and $S_{6}$. According to this feature, different duty ratios are designed to adjust the linear motor's damping force. Nevertheless, because the circuit inevitably has resistance, there is a specific range of equivalent damping, and the control performance is limited. In this mode, the switching signal of switch $S_{6}$ is complementary to $S_{5}$.

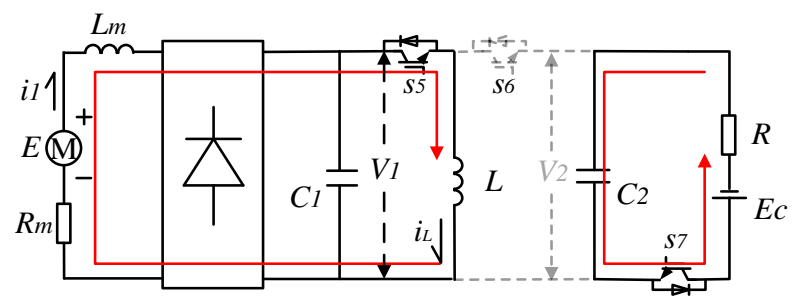

Figure 4 Conduction state of the control circuit in energy regenerative mode

During the time $0<t<D T$, the circuit operation is shown in Figure 4. According to Kirchhoff's theorem, the voltage and current equation of the circuit are obtained:

$$
\left\{\begin{array}{l}
E=L_{m} \frac{d i_{1}}{d t}+V_{1}+R_{m} i_{1} \\
V_{1}=L \frac{d i_{L}}{d t} \\
i_{1}=C_{1} \frac{d V_{1}}{d t}+i_{L}
\end{array}\right.
$$

At the output end, if the voltage value $V_{o}$ of $C_{2}$ is greater than the recovery voltage $E_{c}$, the switch $S_{7}$ is opened; otherwise, no current flows through the battery pack. The current expression is as follows.

$$
C_{2} \frac{d V_{2}}{d t}=\frac{V_{2}-E c}{R}
$$

According to the above formula, the state equation during the conduction period can be obtained.

$\&=\left[\begin{array}{cccc}-\frac{R_{m}}{L_{m}} & 0 & -\frac{1}{L_{m}} & 0 \\ 0 & 0 & \frac{1}{L} & 0 \\ \frac{1}{C_{1}} & -\frac{1}{C_{1}} & 0 & 0 \\ 0 & 0 & 0 & \frac{1}{R C_{2}}\end{array}\right] x+\left[\begin{array}{cc}\frac{1}{L_{m}} & 0 \\ 0 & 0 \\ 0 & 0 \\ 0 & -\frac{1}{R C_{2}}\end{array}\right] u$

Where $x=\left[i_{1}, i_{L}, V_{l}, V_{2}\right]^{T}$ and $u=\left[E, E_{c}\right]^{T}$. When the initial state value is $x_{10}$, Equation 7 can be solved to obtain

$$
x_{1}(t)=e^{A_{1}\left(t-t_{0}\right)} x_{10}+\int_{t_{0}}^{t} e^{A_{1}(t-\tau)} B_{1} u d \tau
$$

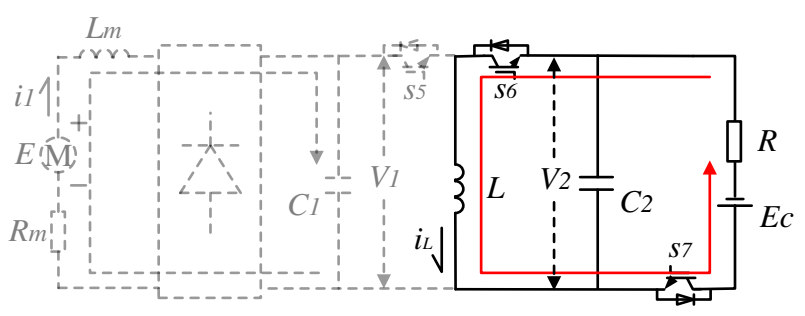

Figure 5 Disconnected state of the control circuit in energy regenerative mode

When $D T<t<T$, it can be seen from Figure 5 that because the inductor current cannot change abruptly at the output, it continues to maintain the initial value to charge the capacitor $C_{2}$ and the recovery battery circuit. The voltage and current equation is:

$$
\left\{\begin{array}{l}
L \frac{d i_{L}}{d t}=-V_{2} \\
i_{L}=C_{2} \frac{d V_{2}}{d t}+\frac{V_{2}-E_{c}}{R}
\end{array}\right.
$$


At the input end, since the induced electromotive force $E$ plus the inductor voltage is greater than $V_{l}$, so continue to charge the capacitor $C_{l}$

$$
\left\{\begin{array}{l}
E+L_{m} \frac{d i_{1}}{d t}=V_{1}+R_{m} i_{1} \\
i_{1}=C_{1} \frac{d V_{1}}{d t}
\end{array}\right.
$$

The state equation during turn-off is obtained by Formulas 9 and 10 as

$$
\&=\left[\begin{array}{cccc}
\frac{R_{m}}{L_{m}} & 0 & \frac{1}{L_{m}} & 0 \\
0 & 0 & 0 & \frac{1}{L} \\
\frac{1}{C_{1}} & 0 & 0 & 0 \\
0 & \frac{1}{C_{2}} & 0 & -\frac{1}{R C_{2}}
\end{array}\right] x+\left[\begin{array}{cc}
-\frac{1}{L_{m}} & 0 \\
0 & 0 \\
0 & 0 \\
0 & \frac{1}{R C_{2}}
\end{array}\right] u
$$

The state of the system is solved as

$$
x_{2}(t)=e^{A_{2}\left(t-t_{0}\right)} x_{20}+\int_{t_{0}}^{t} e^{A_{2}(t-\tau)} B_{2} u d \tau
$$

Assuming the system is in a stable state, the value at the end of turn-on is equal to the initial value at the moment of a turn-off, that is

$$
\left\{\begin{array}{l}
x_{20}=x_{1}(D T) \\
x_{10}=x_{2}(T)
\end{array}\right.
$$

\subsubsection{Energy consumption mode}

In this mode, the car's electric energy is consumed to output the active control force, which greatly improves the ride comfort. The circuit's operating state is similar to that the energy-recovery mode, except that the parameters and input and output have changed.

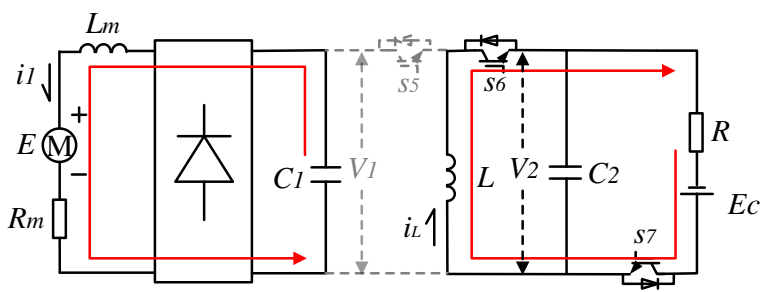

Figure 6 Conduction state of the control circuit in energy regenerative mode

When $0<t<D T$, the circuit is shown in Figure $6, S_{6}$ is on, and $S_{5}$ is off. If the voltage of the capacitor $C_{2}$ is set equal to the power supply voltage $E_{c}$, no current will flow to it.
According to Kirchhoff's theorem, the following equation is obtained.

$$
\left\{\begin{array}{l}
E_{c}=L \frac{d i_{L}}{d t}+R i_{L} \\
V_{1}=L_{m} \frac{d i_{1}}{d t}+R_{m} i_{1}+E \\
i_{1}=C_{1} \frac{d V_{1}}{d t}
\end{array}\right.
$$

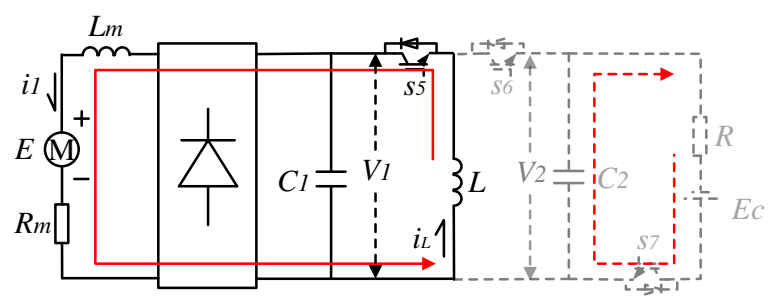

Figure 7 Conduction state of the control circuit in energy regenerative mode

When $D T<t<T, S_{5}$ turns on. On the output side, the inductor current flows to the capacitor $C_{l}$ and the motor while maintaining the value at the previous time.

$$
\left\{\begin{array}{l}
V_{1}=L \frac{d i_{L}}{d t} \\
V_{1}=L_{m} \frac{d i_{m}}{d t}+E+R_{m} i_{1} \\
i_{L}=C_{1} \frac{d V_{1}}{d t}+i_{1}
\end{array}\right.
$$

It can be analyzed from the circuits in the above two modes that the selection of the inductor $L$ is based on the rated current. In order to withstand a larger current, a smaller inductor value is selected, but need a higher switching frequency. The value of the capacitor has a noticeable influence on the current ripple. If $C_{l}$ is selected a larger value, the motor current can be stabilized, but a too-large value will cause a hysteresis deviation at the current zerocrossing or sudden change. Besides, $C_{2}$ has little effect on the motor current. At the same time, both capacitors will withstand the pulse voltage of the inductor $L$, so choose a capacitor with a higher high-frequency withstand voltage.

\section{Current controller}

\subsection{Fuzzy PID controller}

Because the Buck-Boost converter has non-linear characteristics, the mathematical model's application range derived by hypothesis or the estimated model obtained by identification is limited, and the ideal output current cannot be output accurately, quickly, and accurately. If the 
traditional PID controller is selected as the current controller, there will be a contradiction between zero overshoot and rapidity. Simultaneously, the input induced electromotive force and output control current of the controller are both time-varying. They are failing to meet higher control performance requirements. Therefore, the fuzzy control algorithm is introduced into PID control to realize the adaptive adjustment of control parameters and improve its control performance [26]. The principle of the current controller is shown in Figure 8.

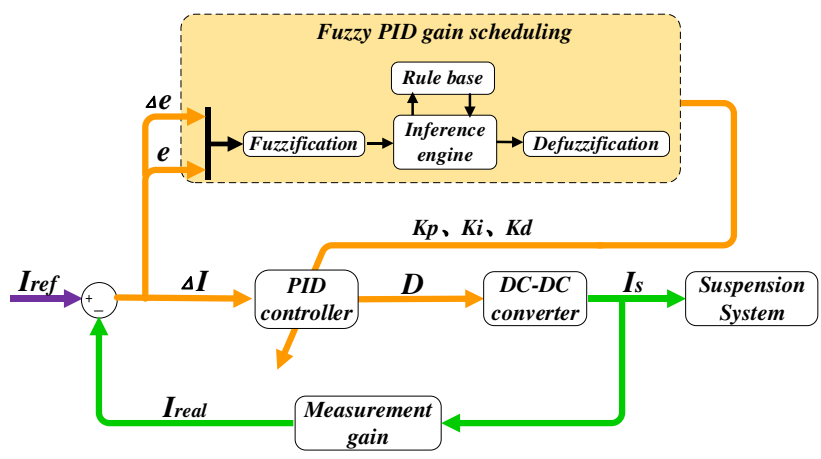

Figure 8 Fuzzy PID controller structure
The adaptive fuzzy PID controller takes the error $e$ and the error differential de as input to adjust the PID control parameters for different situations. The output results of fuzzy inference are $K_{p}, K_{i}, K_{d}$, and then the duty cycle $D$ is calculated by the PID controller.

\subsection{Fuzzy membership function and control rules}

The core of adaptive fuzzy PID control lies in the design of fuzzy membership functions and control rules. The fuzzy set of input variables and output variables in this paper is seven fuzzy subsets: [(PB), (PM), (PS), (ZE), (NS), (NM), (NB)], membership functions are all represented by triangles.

The database stores the membership functions of all variables' fuzzy subsets and provides data to the inference engine in the inference of fuzzy relation equations. For nonlinear, time-varying, and challenging to describe with proper transfer functions, various tuning experiences and knowledge of PID parameters can be summarized. When the deviation is large, it mainly eliminates the deviation as soon as possible; when the deviation is small, it prevents overshoot and improves system stability. According to control experience and many experiments, fuzzy rules are formulated, as shown in the Table1.

Table 1 Fuzzy rule table

\begin{tabular}{cccccccc}
\hline & \multicolumn{7}{c}{$d e$} \\
\cline { 2 - 8 } & $\mathrm{NB}$ & $\mathrm{NM}$ & $\mathrm{NS}$ & $\mathrm{ZO}$ & $\mathrm{PS}$ & $\mathrm{PM}$ & $\mathrm{PB}$ \\
\hline $\mathrm{NB}$ & $\mathrm{NB} / \mathrm{PB} / \mathrm{NB}$ & $\mathrm{NB} / \mathrm{PB} / \mathrm{NB}$ & $\mathrm{NB} / \mathrm{PB} / \mathrm{NB}$ & $\mathrm{NB} / \mathrm{ZO} / \mathrm{NB}$ & $\mathrm{PS} / \mathrm{NB} / \mathrm{PS}$ & $\mathrm{PM} / \mathrm{NB} / \mathrm{PM}$ & $\mathrm{PB} / \mathrm{NB} / \mathrm{PB}$ \\
$\mathrm{NM}$ & $\mathrm{NM} / \mathrm{PB} / \mathrm{NM}$ & $\mathrm{NM} / \mathrm{PM} / \mathrm{NM}$ & $\mathrm{NB} / \mathrm{PS} / \mathrm{NB}$ & $\mathrm{NM} / \mathrm{ZO} / \mathrm{NB}$ & $\mathrm{ZO} / \mathrm{NB} / \mathrm{ZO}$ & $\mathrm{PS} / \mathrm{NM} / \mathrm{PS}$ & $\mathrm{PB} / \mathrm{NB} / \mathrm{PB}$ \\
$\mathrm{NS}$ & $\mathrm{NS} / \mathrm{PS} / \mathrm{NS}$ & $\mathrm{NM} / \mathrm{PS} / \mathrm{NM}$ & $\mathrm{NB} / \mathrm{NS} / \mathrm{NB}$ & $\mathrm{NS} / \mathrm{ZO} / \mathrm{NB}$ & $\mathrm{NS} / \mathrm{NS} / \mathrm{NS}$ & $\mathrm{ZO} / \mathrm{NS} / \mathrm{ZO}$ & $\mathrm{PM} / \mathrm{NM} / \mathrm{PM}$ \\
$\mathrm{ZO}$ & $\mathrm{ZO} / \mathrm{ZO} / \mathrm{ZO}$ & $\mathrm{NS} / \mathrm{ZO} / \mathrm{NS}$ & $\mathrm{NM} / \mathrm{NM} / \mathrm{NM}$ & $\mathrm{ZO} / \mathrm{ZO} / \mathrm{ZO}$ & $\mathrm{NM} / \mathrm{ZO} / \mathrm{NM}$ & $\mathrm{NS} / \mathrm{ZO} / \mathrm{NS}$ & $\mathrm{PS} / \mathrm{ZO} / \mathrm{PS}$ \\
$\mathrm{PS}$ & $\mathrm{PS} / \mathrm{NM} / \mathrm{PS}$ & $\mathrm{ZO} / \mathrm{NS} / \mathrm{ZO}$ & $\mathrm{NS} / \mathrm{NM} / \mathrm{NS}$ & $\mathrm{NS} / \mathrm{ZONS}$ & $\mathrm{NB} / \mathrm{PS} / \mathrm{NB}$ & $\mathrm{NM} / \mathrm{PS} / \mathrm{NM}$ & $\mathrm{ZO} / \mathrm{PS} / \mathrm{ZO}$ \\
$\mathrm{PM}$ & $\mathrm{PM} / \mathrm{NB} / \mathrm{PM}$ & $\mathrm{PS} / \mathrm{NM} / \mathrm{PS}$ & $\mathrm{PS} / \mathrm{NB} / \mathrm{PS}$ & $\mathrm{NM} / \mathrm{ZO} / \mathrm{NM}$ & $\mathrm{NB} / \mathrm{PB} / \mathrm{NB}$ & $\mathrm{NB} / \mathrm{PM} / \mathrm{NB}$ & $\mathrm{NS} / \mathrm{PM} / \mathrm{NS}$ \\
$\mathrm{PB}$ & $\mathrm{PB} / \mathrm{NB} / \mathrm{PB}$ & $\mathrm{PM} / \mathrm{NB} / \mathrm{PM}$ & $\mathrm{PB} / \mathrm{NB} / \mathrm{PB}$ & $\mathrm{NB} / \mathrm{ZO} / \mathrm{NB}$ & $\mathrm{NB} / \mathrm{PB} / \mathrm{NB}$ & $\mathrm{NB} / \mathrm{PB} / \mathrm{NB}$ & $\mathrm{NM} / \mathrm{PM} / \mathrm{NM}$ \\
\hline
\end{tabular}

\section{Design of Suspension Control Strategy}

According to the analysis of the energy flow state of the motor, Figure 9 shows that the motor can run in three intervals. Among them, in zone I and II, the motor consumes battery energy to suppress vibration. And in zone III, the motor acts as a generator to recover the vibration energy and store it in the battery. According to the characteristics of the controller, two operating strategies are designed. When the road is rough, or the battery pack is low, the energy-recovery semi-active control is used to recover energy. In this mode, only the passive damping force can be generated to offset the road vibration. Under the energy consumption control, the motor will obtain the control force from the energy consumption of the battery. This control strategy significantly increases the range of the control current and improves the vibration reduction effect.

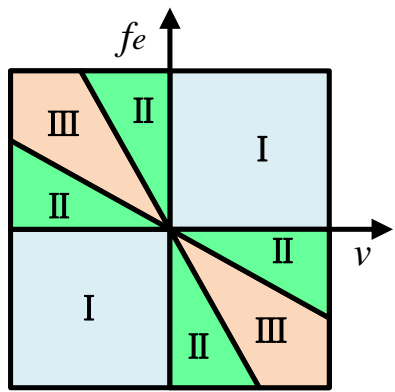

Figure 9 The operating zones of the motor 


\subsection{Energy Regenerative Control Strategy}

In this mode, the linear motor is always in the generator state, and the damping can be adjusted by changing the duty cycle. So, if the equivalent damping is the value where the recovered power is the largest, the most recovered energy is obtained, but other performances have also deteriorated. To avoid the existence of the above contradictions, a skyhook control [27] with on-off characteristics is adopted.

$$
c_{s}=\left\{\begin{array}{lc}
c_{\text {max }}, & \&(\underset{s}{\&}-\underset{t}{\&})>0 \\
c_{\text {min }}, & \text { else }
\end{array}\right.
$$

In the formula: $C_{\max }$ shall not exceed the maximum equivalent damping of the linear motor, and $C_{\min }$ selects the equivalent damping coefficient near the maximum recovered power.

\subsection{Active Control Strategy}

Under this strategy, vehicle body acceleration is the primary optimization index. Furthermore, the influence of suspension stroke, tire deflection and handling force also need to be considered. Therefore, this paper adopts the $L Q G$ optimal control strategy [28] to ensure the dynamic performance of the suspension. The performance index function of the output regulator can be written as follows:

$$
J=\lim _{T \rightarrow \infty} \frac{1}{T} \int_{0}^{T}\left[q_{1}+q_{2}\left(x_{s}-x_{u}\right)^{2}+q_{3}\left(x_{u}-x_{r}\right)^{2}+r F^{2}\right] d t
$$

Where: $T$ is the vehicle travel time, $q_{1}, q_{2}, q_{3}$ and $r$ are the weighting factors of body vertical acceleration, suspension dynamic disturbance, suspension dynamic disturbance and active output force. The weight factor selection is closely related to the researcher's choice of the focus of improving the performance of the suspension.

\section{Numerical simulation and results discussion}

\subsection{Controller Performance}

For the controller system designed in this paper, the control variable is the size of the input duty cycle, which not only controls the force of the actuator but also affects the recovery power of the battery. In order to better analyze the performance of the actuator, this paper discusses the changes in equivalent damping, recovered power and recovery efficiency by changing the relative speed and duty cycle of the suspension in the energy regenerative mode. The results of each state are obtained under stable operation. Finally, the impact of the recovery voltage on the shock absorber is discussed. The parameters of the control circuit are shown in Table 2.
Table 2 Control circuit simulation parameters

\begin{tabular}{cccc}
\hline Symbol & Value & Symbol & Value \\
\hline$K_{i}$ & $115 \mathrm{~N} / \mathrm{A}$ & $L_{m}$ & $3.3 \mathrm{mH}$ \\
$K_{v}$ & $76.6 \mathrm{~V} /(\mathrm{m} / \mathrm{s})$ & $L$ & $33 \mathrm{uH}$ \\
$R_{m}$ & 5.1 & $C_{l}$ & $6.8 \mathrm{uF}$ \\
$R$ & 0.1 & $C_{2}$ & $460 \mathrm{uF}$ \\
\hline
\end{tabular}

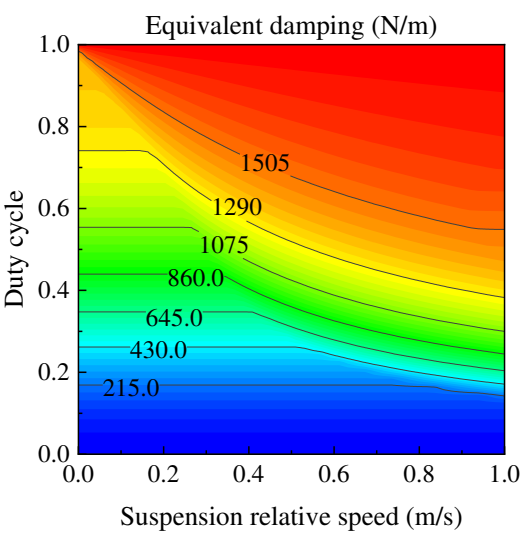

(a)

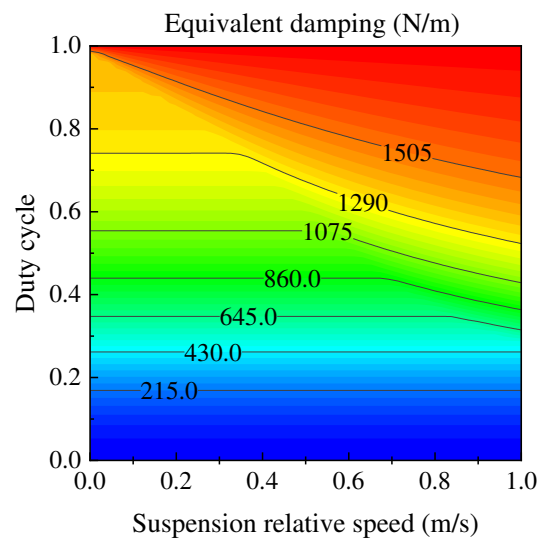

(b)

Figure 10 Equivalent damping under $12 \mathrm{~V}(\mathrm{a})$ and $24 \mathrm{~V}(\mathrm{~b})$ recovery voltage

It can be seen from Figure 10 that the recovery voltage will not affect the value range of the equivalent damping. So the performance of the energy harvesting controller is relatively stable. As the duty cycle changes, the equivalent damping can be adjusted from 0 to $1716 \mathrm{~N} / \mathrm{m}$, and the relative speed affects the rate of change of the damping.

As shown in Figure 11, the input voltage has an undeniable influence on the recovered power. So the recovery capacity on a smooth road is relatively weak. The high recovery power area is affected by the recovery voltage. Combined with the previous equivalent damping diagram, the equivalent damping of the highest power of different recovery voltages is very close, varying around 800 , which provides a basis for the design of the energy regenerative controller. 


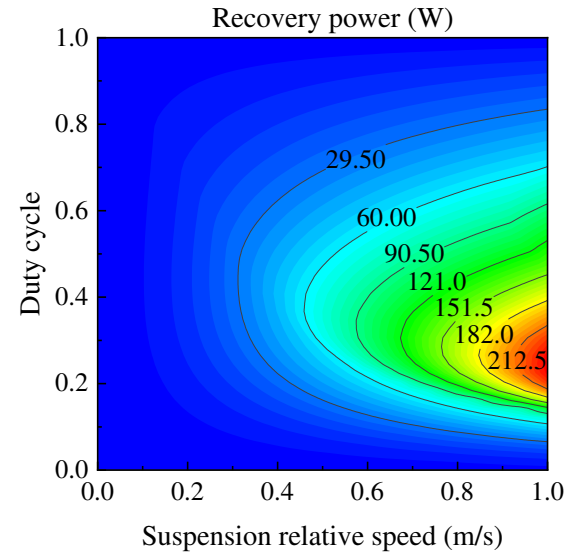

(a)

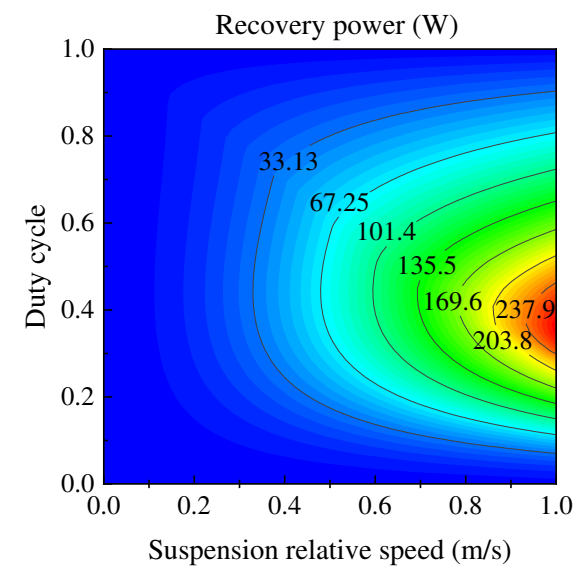

(b)

Figure 11 Recovery power under $12 \mathrm{~V}(\mathrm{a})$ and $24 \mathrm{~V}(\mathrm{~b})$ recovery voltage

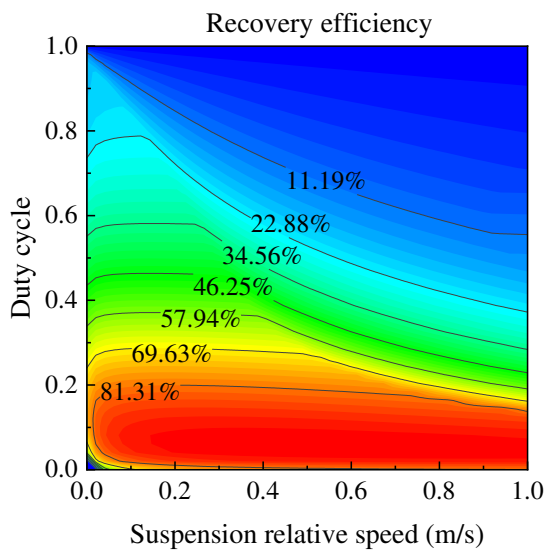

(a)

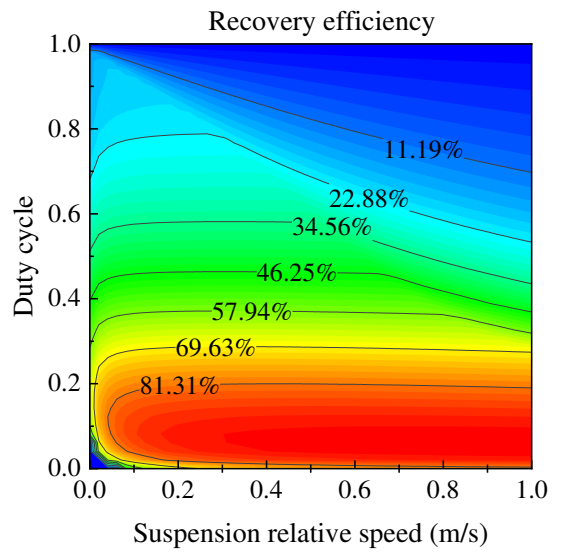

(b)

Figure 12 Recovery efficiency under 12V(a) and 24V(b) recovery voltage

The changing trend of recovery efficiency is similar to the equivalent damping, as shown in Figure 12. The higher recovery efficiency point is closer to the ' 0 ' duty cycle. The reason is that when the duty ratio is low, the recovery current will be cut off, and the resistance consumption is relatively small. With the increase of the duty cycle, the charging voltage and circuit resistance consumption also gradually increases, which leads to a decrease in recovery efficiency.

\subsection{Suspension Performance Analysis}

In order to verify the effectiveness of the designed controller, simulations under various road conditions were performed in MATLAB® / SIMULINK® software. The simulation results of two different control modes were compared with those of traditional passive suspension systems at a speed of $15 \mathrm{~m} / \mathrm{s}$ on a Class D road, and the results of the other three different roads A, B, and C, are compared in Table 4 with the root mean square value. Table 3 shows the parameters used in the simulation.

Table 3 Suspension and control circuit parameters

\begin{tabular}{cccc}
\hline Symbol & Value & Symbol & Value \\
\hline$m_{s}$ & $343 \mathrm{~kg}$ & $c_{\max }$ & $1600 \mathrm{~N} / \mathrm{m}^{2}$ \\
$m_{u}$ & $40 \mathrm{~kg}$ & $c_{\min }$ & $750 \mathrm{~N} / \mathrm{m}^{2}$ \\
$k_{s}$ & $14500 \mathrm{~N} / \mathrm{m}$ & $n_{0}$ & 0.1 \\
$k_{t}$ & $190000 \mathrm{~N} / \mathrm{m}$ & $f_{0}$ & 0.011 \\
$c_{s}$ & $1385.4 \mathrm{~N} / \mathrm{m}^{2}$ & & \\
\hline
\end{tabular}

The circuit's switching frequency is $2 \times 10^{4} \mathrm{~Hz}$, and the range of errors $e$ and $d e$ of fuzzy control are both set to [$0.1,0.1]$ and $\left[-10^{11}, 10^{11}\right]$, but the range of PID parameters is different for the two control strategies. The range of $K_{p}, K_{i}$, and $K_{d}$ under active control are [0,2 $\left.\times 10^{-3}\right],[100,300]$, and $\left[0,1 \times 10^{-3}\right]$, and the range of the three parameters under energy regenerative control is [0,2],[2000,3000], and $[0,1]$. 
According to the controller's characteristics, the recovery voltage is selected to be $24 \mathrm{v}$, and the voltage for energy consumption control is set to $90 \mathrm{~V}$ to avoid insufficient output voltage range. From Figure 13, the control force in the two modes is in good agreement with the ideal value, and the ripple of the control force is smaller because the motor inductance is much larger than the power inductor.

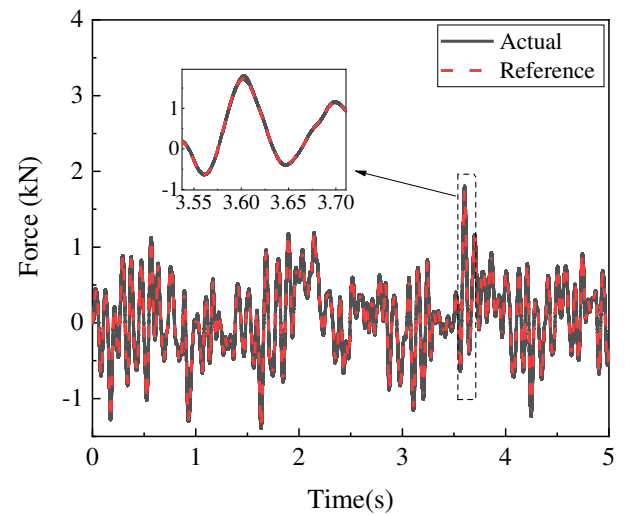

(a)
Furthermore, active control's tracking effect is better than energy recovery control because the former provides greater input current, which improves the response speed. The regenerative energy control has overshoot when the control force changes suddenly, but it also can meet the control requirements.

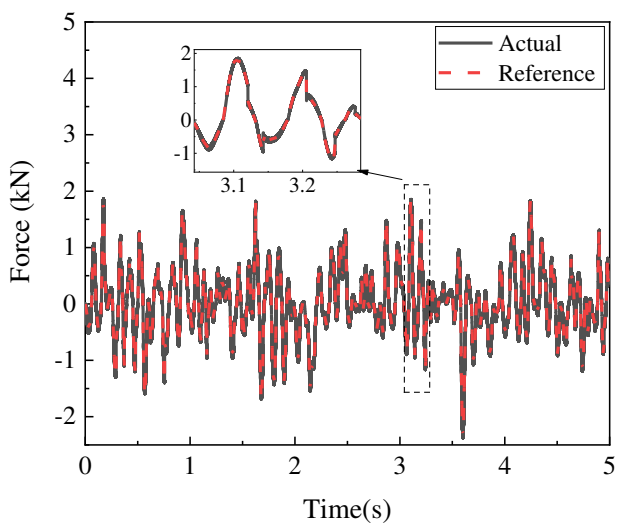

(b)

Figure 13 Comparison of ideal and actual control forece in active mode(a) and energy-regenerative mode(b)

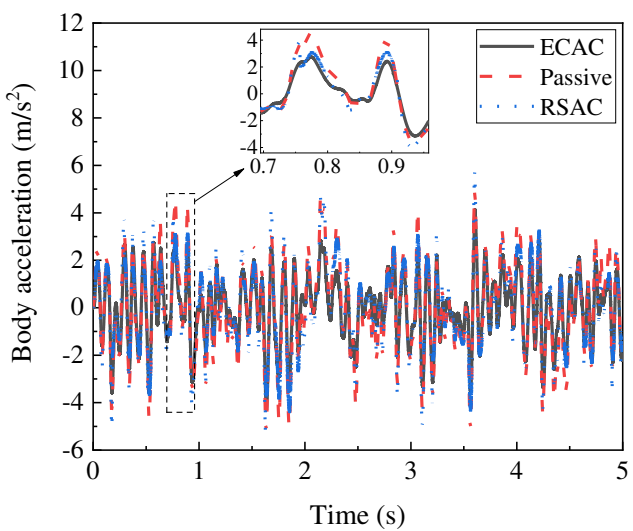

(a)

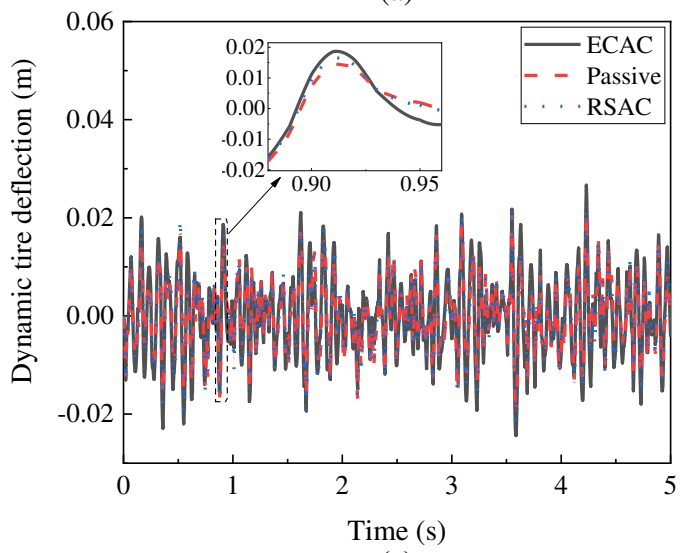

(c)

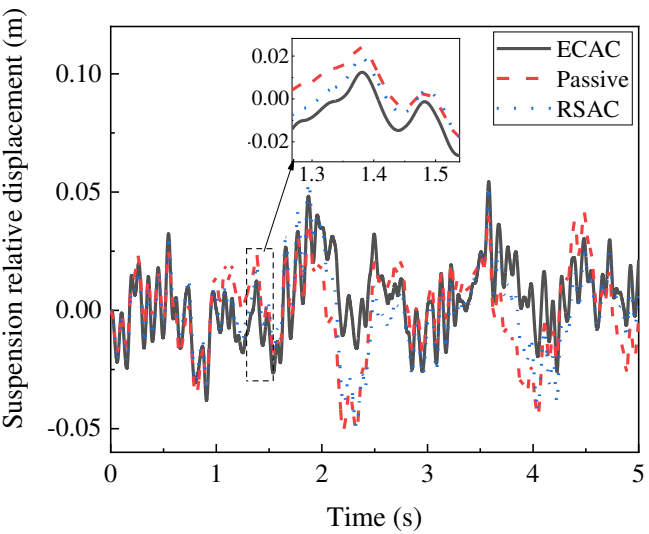

(b)

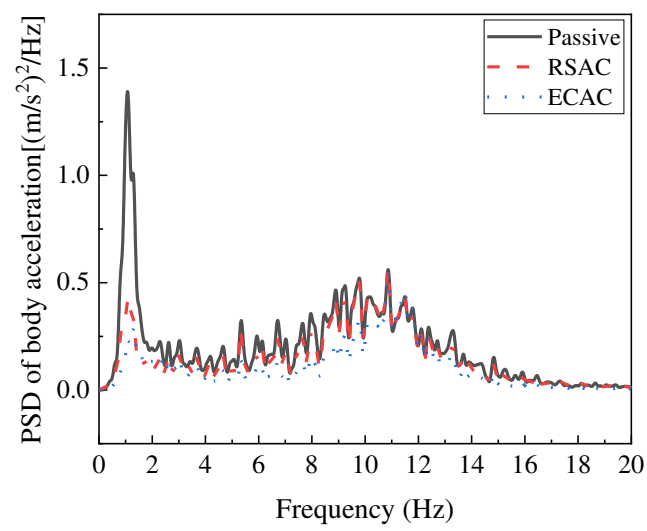

(d) 


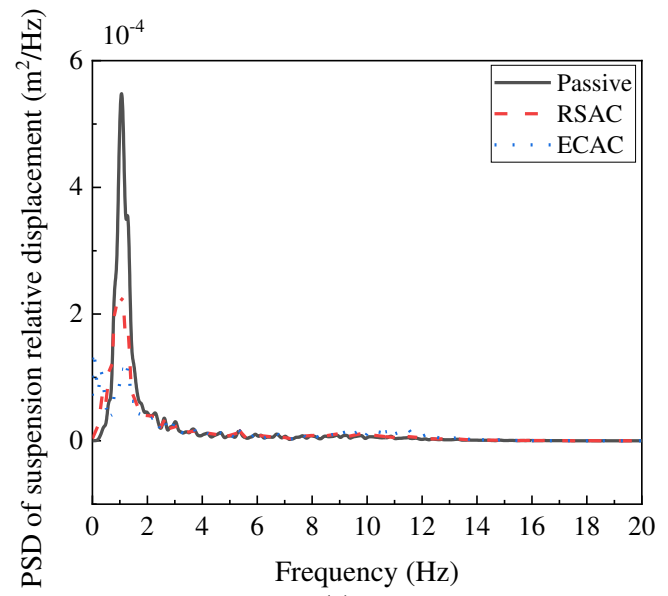

(e)

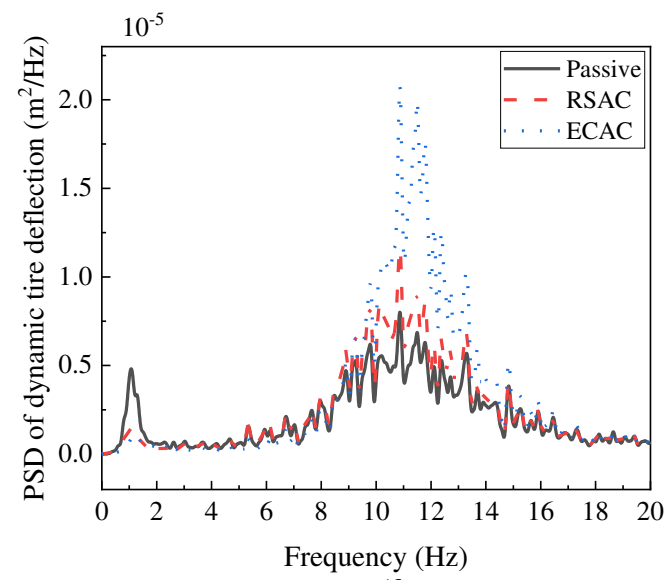

(f)

Figure 14 Comparison of dynamic performance: Body acceleration (a) time domain response and (d) frequency domain response; suspension relative displacement in (b) time domain response and (e) frequency domain; Response of dynamic tire deflection in(c) time domain and (f) frequency domain

The vehicle body acceleration (BA) response results in Figure 14(a) and Table 3 show that both active control and energy recovery control strategies can improve ride comfort, and the improvement effects are increased by $26 \%$ and $10 \%$, respectively. At the same time, control effect does not change with driving conditions. Besides, it can be seen from Figure 14(d) that the two control methods effectively suppress the vibration near $1 \mathrm{~Hz}$, but the improvement effect of the RSAC is not as good as the ECAC in other frequency because active control has a more extensive control current range.

It can be seen from the Figure14 and Table3, The suspension relative displacement (SRD) of the RSAC and ECAC modes is reduced by about $10 \%$ in the time domain, while the frequency domain is better than the passive suspension. They are both ensures the suspension's regular operation and does not interfere with the body. The dynamic tire deflection (DTD) under the two control methods has deteriorated, especially in the high-frequency part, where the active control is much larger than the passive suspension, resulting in reduced road handing. Nevertheless, as long as the tire's relative displacement is less than $0.013 \mathrm{~m}$, the tire has good contact with the ground. At the same time, it can be seen from the table that the two control effects remain stable under different road conditions.

Table 3. RMS of performance indicators under different road conditions

\begin{tabular}{ccccccc}
\hline & \multicolumn{3}{c}{ Road A } & \multicolumn{3}{c}{ Road B } \\
\cline { 2 - 7 } & ECAC & RSAC & passive & ECAC & RSAC & passive \\
\hline $\mathrm{BA}\left(\mathrm{m} / \mathrm{s}^{2}\right)$ & 0.1822 & 0.2198 & 0.2464 & 0.3643 & 0.4396 & 0.4927 \\
$\mathrm{SRD}(\mathrm{mm})$ & 2.147 & 2.158 & 2.409 & 4.294 & 4.315 & 4.818 \\
$\mathrm{DTD}(\mathrm{mm})$ & 1.049 & 0.9135 & 0.8501 & 2.098 & 1.827 & 1.7 \\
\hline \hline & & Road C & & & Road D & \\
\cline { 2 - 7 } & ECAC & RSAC & passive & ECAC & RSAC & passive \\
\hline $\mathrm{BA}\left(\mathrm{m} / \mathrm{s}^{2}\right)$ & 0.7286 & 0.8793 & 0.9855 & 1.457 & 1.759 & 1.971 \\
$\mathrm{SRD}(\mathrm{mm})$ & 8.589 & 8.631 & 9.636 & 17.18 & 17.26 & 19.27 \\
$\mathrm{DTD}(\mathrm{mm})$ & 4.196 & 3.654 & 3.4 & 8.392 & 7.308 & 6.801 \\
\hline
\end{tabular}




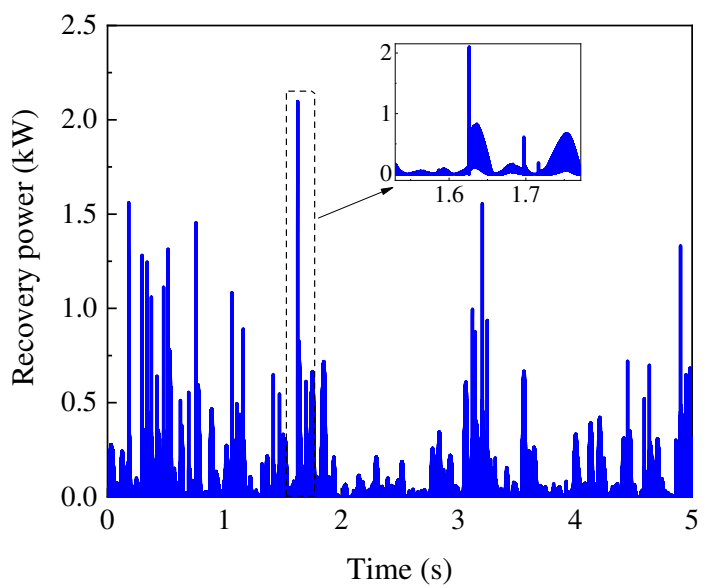

(a)

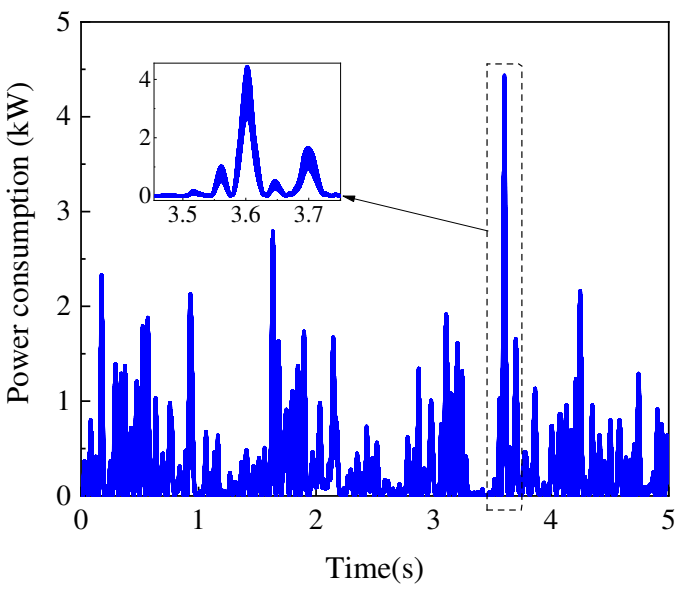

(b)

Figure 15 (a) Instantaneous recovery power in RSAC; (b)instantaneous power consumption in ECAC

Table 4 Controller performance on different road conditions

\begin{tabular}{ccccc}
\hline & Road A & Road B & Road C & Road D \\
\hline Average recovery power (W) & 0.56 & 2.43 & 9.96 & 39.50 \\
Maximum average recovery power (W) & 1.39 & 5.64 & 22.49 & 87.77 \\
Average power consumption (W) & 4.21 & 16.75 & 67.06 & 270.2 \\
Recovery efficiency & $19.92 \%$ & $21.57 \%$ & $22.16 \%$ & $21.94 \%$ \\
\hline
\end{tabular}

The instantaneous power consumption and regeneration of the electromagnetic shock absorber are shown in Figure 15, respectively. Due to the recovery circuit have small resistance, the charging current drops quickly, resulting in high-frequency fluctuations in the recovery power. However, on a D-class road with a driving speed of $15 \mathrm{~m} / \mathrm{s}$, the controller's average recovered power can reach $39.5 \mathrm{~W}$, while the average power consumption of active control under the same conditions is $270.2 \mathrm{~W}$. Although the energy recovered is less than the consumption, only a reasonable switch between the two working modes can achieve energy balance. Then, from the data in the Table4, the road level has a significant influence on the control, and the recovered power in the low-level road RSAC mode is feeble, the power consumption of active control is reduced accordingly. In RSAC mode, part of the energy regeneration capability is sacrificed to improve ride comfort, while in ECAC mode, other performance will not be reduced under the premise of ensuring good ride comfort.

\section{Conclusions}

According to the working characteristics of linear motors, this paper introduces the design and simulation of a new type of multifunctional shock absorber based on the two-way buck-boost circuit. Two different control modes (energyconsuming active control and Regenerative semi-active control) are proposed. By changing the circuit switch, the control force and working mode can be adjusted, which provides a physical structure basis for different suspension control strategies. In order to accurately output the ideal control force, a fuzzy PID current controller that does not require a control object model is selected, and it also solves the nonlinear problem of the Buck-Boost circuit. Besides, by analyzing the influence of the circuit parameters on the performance of the controller, the appropriate electrical components are selected. The simulation results show that the proposed controller can achieve the required control function, and the control effect under different driving conditions does not change much. In terms of ride comfort optimization, energy-consuming active control has the best effect, but cost more energy. In the RSAC mode, it not only ensures good damping performance but also recovers a certain amount of energy. If the two control modes can be switched reasonably, the proposed controller can meet different riding requirements and make up for the shortcomings of traditional strategies which use single performance optimization.

\section{References}

[1] H Li, J Yu, C Hilton, H Liu. Adaptive Sliding-Mode Control for Nonlinear Active Suspension Vehicle Systems Using T-S Fuzzy Approach. IEEE Transactions on Industrial Electronics 2013, 60(8): $3328-3338$ 
[2] H Chen, K H Guo. Constrained H/sub /spl infin// control of active suspensions: an LMI approach. IEEE Transactions on Control Systems Technology 2005, 13(3): 412-421.

[3] W Sun, H. Gao, O Kaynak. Finite Frequency Control for Vehicle Active Suspension Systems. IEEE Transactions on Control Systems Technology 2011, 19(2): 416-422.

[4] J Cao, P Li, H Liu. An Interval Fuzzy Controller for Vehicle Active Suspension Systems. IEEE Transactions on Intelligent Transportation Systems 2010, 11(4): 885-895.

[5] I Martins, J Esteves, G D Marques, et al. Permanent-Magnets Linear Actuators Applicability in Automobile Active Suspensions. IEEE Transactions on Vehicular Technology 2006, 55(1): p.86-94.

[6] L Segel, X P Li. Vehicular resistance to motion as influenced by road roughness and highway alignment. Australian Road Research,1982,12(4): 211-222.

[7] M AAAbdelkareem, L Xu, X Guo, et al. Energy harvesting sensitivity analysis and assessment of the potential power and full car dynamics for different road modes. Mechanical Systems and Signal Processing, 2018, 110: 307-332.

[8] P Múčka. Energy-harvesting potential of automobile suspension. Vehicle System Dynamics, 2016: 1-20.

[9] C Riese, O Stump, F Gauterin. Investigation of the energy recuperation potential of the damper system for a compact class passenger car. International Journal of Vehicle Design, 2017, 74(4): 281.

[10] M A A Abdelkareem, L Xu, M K A Ali, et al. Vibration energy harvesting in automotive suspension system: A detailed review. Applied energy 2018, 229: 672-699

[11] S Zhu, W A Shen, Y L Xu. Linear electromagnetic devices for vibration damping and energy harvesting: Modeling and testing. Engineering Structures 2012, 34: 198-212.

[12] R Zhang, X Wang, Z Liu. A novel regenerative shock absorber with a speed doubling mechanism and its Monte Carlo simulation. Journal of Sound and Vibration 2018, 417: 260-276.

[13] S Zhu, W Shen, Y Xu. Linear electromagnetic devices for vibration damping and energy harvesting: Modeling and testing. Engineering Structures, 2012, 34: 198-212.

[14] R Ding, R Wang, X Meng. Energy-saving control strategy design and structure realization for electromagnetic active suspension. ARCHIVE Proceedings of the Institution of Mechanical Engineers Part C Journal of Mechanical Engineering Science 1989-1996 (vols 203210), 2018: 233.

[15] P S Zhang. Design of electromagnetic shock absorbers for energy harvesting from vehicle suspensions. Master's Thesis, Stony Brook University, Stony Brook, NY, USA, 2010.

[16] S Liu, H Wei, W Wang. Investigation on some key issues of regenerative damper with rotary motor for automobile suspension. In: Proceedings of 2011 International Conference on Electronic \& Mechanical Engineering and Information Technology. IEEE 2011: 1435-1439.

[17] A Tonoli, N Amati, J G Detoni, et al. Modelling and validation of electromechanical shock absorbers. Vehicle System Dynamics 2013, 51(8): 1186-1199.

[18] Z Li, L Zuo, G Luhrs, et al. Electromagnetic energy-harvesting shock absorbers: design, modeling, and road tests. IEEE Transactions on Vehicular Technology 2013, 62(3): 1065-1074.

[19] Z Zhang, X Zhang, W Chen, et al. A high-efficiency energy regenerative shock absorber using supercapacitors for renewable energy applications in range extended electric vehicle. Applied Energy, 2016, 178: 177-188.
[20] S Guo, Y Liu, L Xu, et al. Performance evaluation and parameter sensitivity of energy-harvesting shock absorbers on different vehicles. Vehicle System Dynamics, 2016:918-942.

[21] S A Chen, X Li, L J Zhao, et al. Development of a control method for an electromagnetic semi-active suspension reclaiming energy with varying charge voltage in steps. International Journal of Automotive Technology 2015, 16(5): 765-773.

[22] L Xie, J Li, X. Li, et al. Damping-tunable energy-harvesting vehicle damper with multiple controlled generators: design, modeling and experiments. Mechanical Systems \& Signal Processing 2018,99: 859-872.

[23] D Shi, L Chen, R Wang, et al. Design and experiment study of a semiactive energy-regenerative suspension system. Smart Materials \& Structures 2014, 24(1): 15001-15012(12).

[24] D H Shi, L Chen, R C Wang, et al. Research on energy-regenerative performance of suspension system with semi-active control. Journal of Vibration Engineering \& Technologies, 2019, 7(5): 465-475.

[25] Z Yonglin, Z Jiafan. Numerical simulation of stochastic road process using white noise filtration. Mechanical Systems and Signal Processing, 2006, 20(2): 363-372.

[26] Y Wang, Q Jin, R Zhang. Improved fuzzy PID controller design using predictive functional control structure. ISA Transactions, 2017:354363.

[27] K S Hong, H C Sohn, J K Hedrick. Modified Skyhook Control of Semi-Active Suspensions: A New Model, Gain Scheduling, and Hardware-in-the-Loop Tuning. Journal of Dynamic Systems Measurement and Control, 2002, 124(1):158-167.

[28] P Hui, C Ying, C Jianan, et al. Design of LQG Controller for Active Suspension without Considering Road Input Signals. Shock and Vibration,2017,(2017-02-27), 2017, 2017:1-13.

\section{Declaration \\ Funding}

Supported by the National Natural Science Foundation of China (Grant No. 51705051); Basic Natural Science and Frontier Technology Research Program (Grant No. ccstc2017jcyjAX0169); China Postdoctoral Science Foundation (Grant Nos. 2018M643420, 2019T120813); Open Foundation of the State Key Laboratory of Mechanical Transmission (Grant No. SKLMT-KFKT- 201804)

\section{Availability of data and materials}

The datasets supporting the conclusions of this article are included within the article.

\section{Authors' contributions}

$\mathrm{XC}$ was in charge of the whole trial; SH wrote the manuscript; TH and DP assisted with structure and language of the manuscript. All authors read and approved the final manuscript.

\section{Competing interests}

The authors declare no competing financial interests.

\section{Consent for publication}


Not applicable

\section{Ethics approval and consent to participate}

Not applicable

\section{Biographical notes}

Xing Chen, born in 1985, is currently an associate professor at Chongqing University of Arts and Sciences, China. He received his $\mathrm{PhD}$ degree from Beijing Institute of Technology, China, in 2015. His research interests include vehicle dynamics and control, transmission technology and theory.

E-mail: bit_cx@163.com

Sen Han, born in 1995, is currently a master candidate at School of Mechatronics \& Vehicle Engineer, Chongqing Jiaotong University, China.

Tian-Hong Luo, born in 1975, is currently an professor at Chongqing University of Arts and Sciences, China. He received his $\mathrm{PhD}$ degree from Chongqing University, China, in 2005. His research interests include vehicle dynamics and control, transmission technology and theory.

Dan Peng, born in 1997, is currently a master candidate at School of Mechatronics \& Vehicle Engineer, Chongqing Jiaotong University, China.

Shui-Li Zheng, born in 1996, is currently a master candidate at School of Mechatronics \& Vehicle Engineer, Chongqing Jiaotong University, China. 


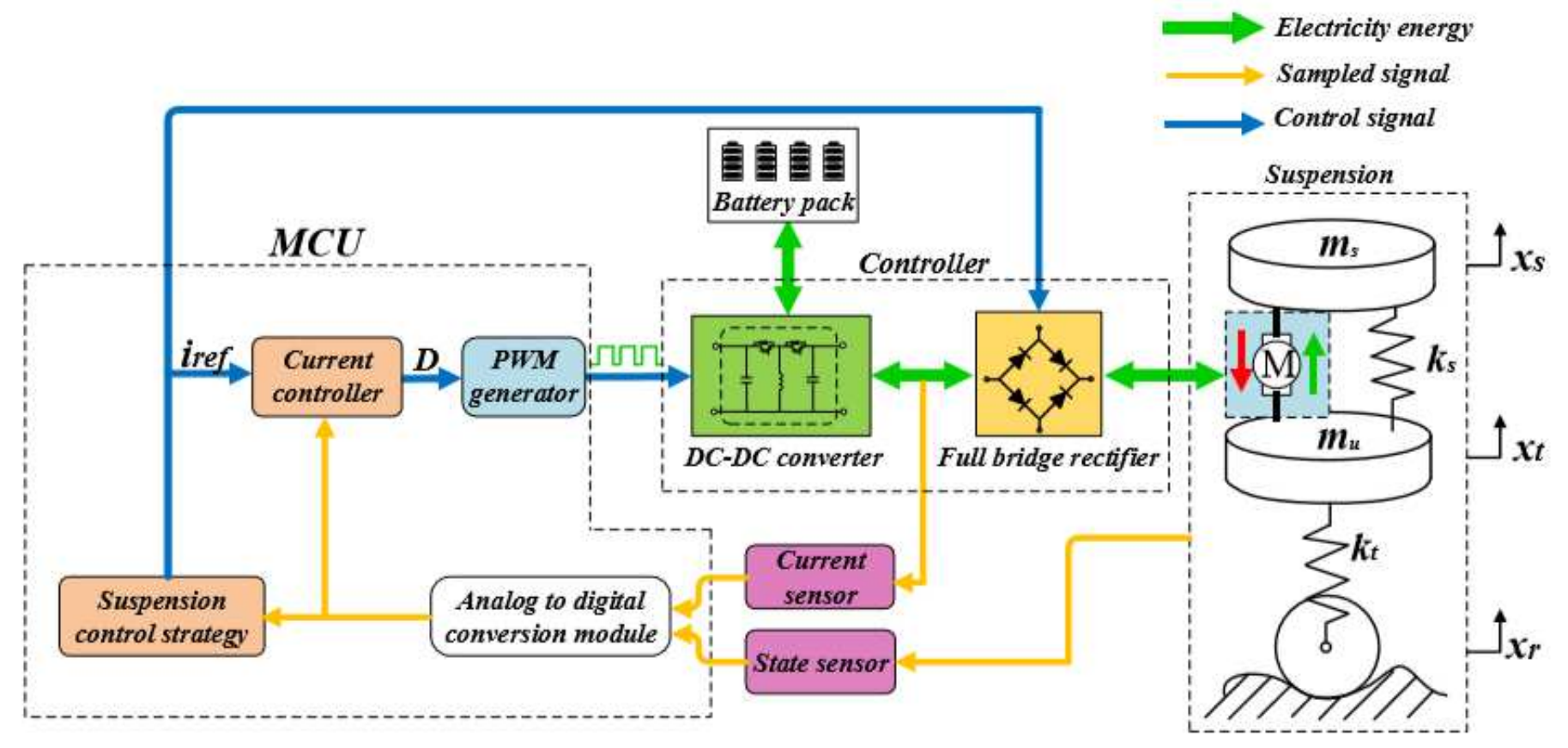

Figure 1

Topology of the multifunctional suspension system

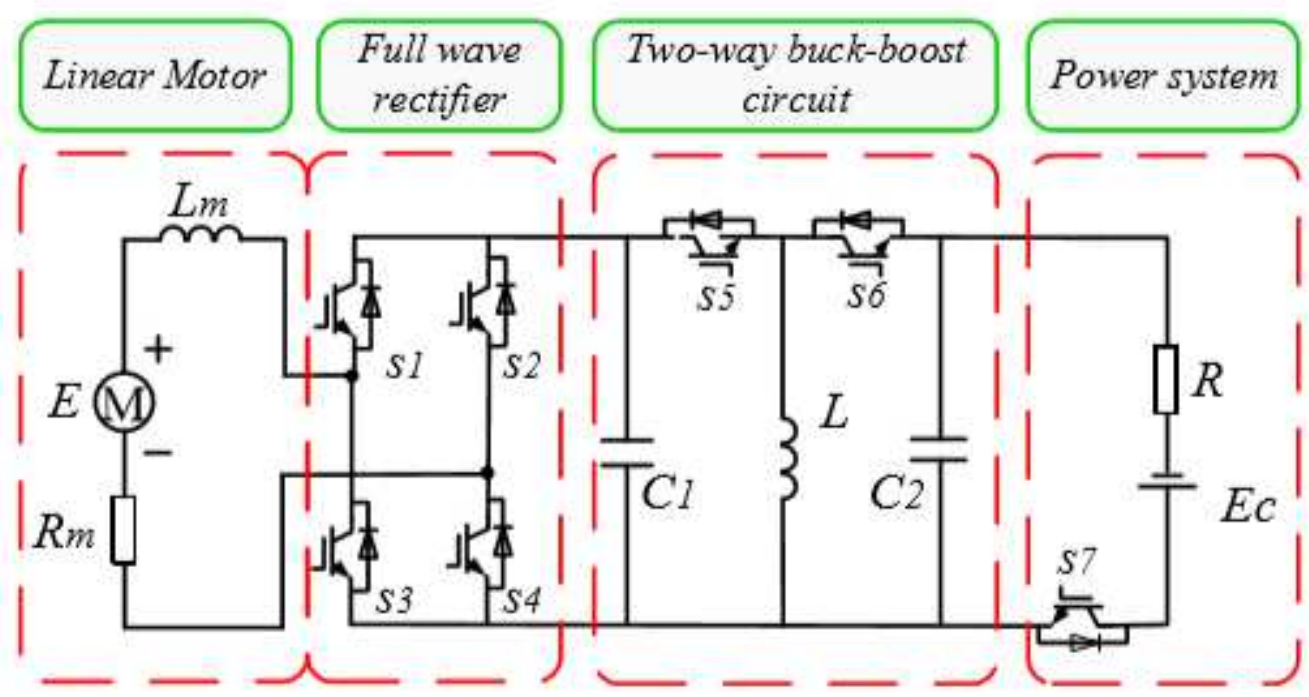

Figure 2

Controller circuit model 


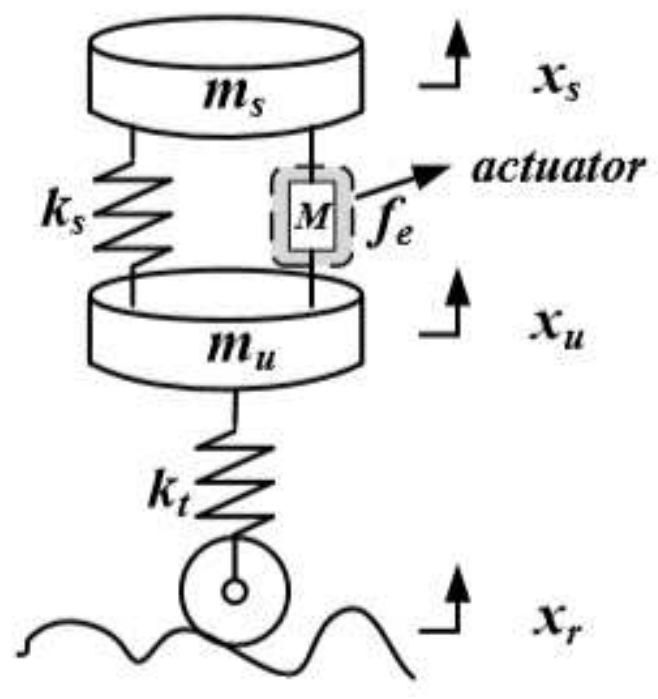

Figure 3

Quarter vehicle model

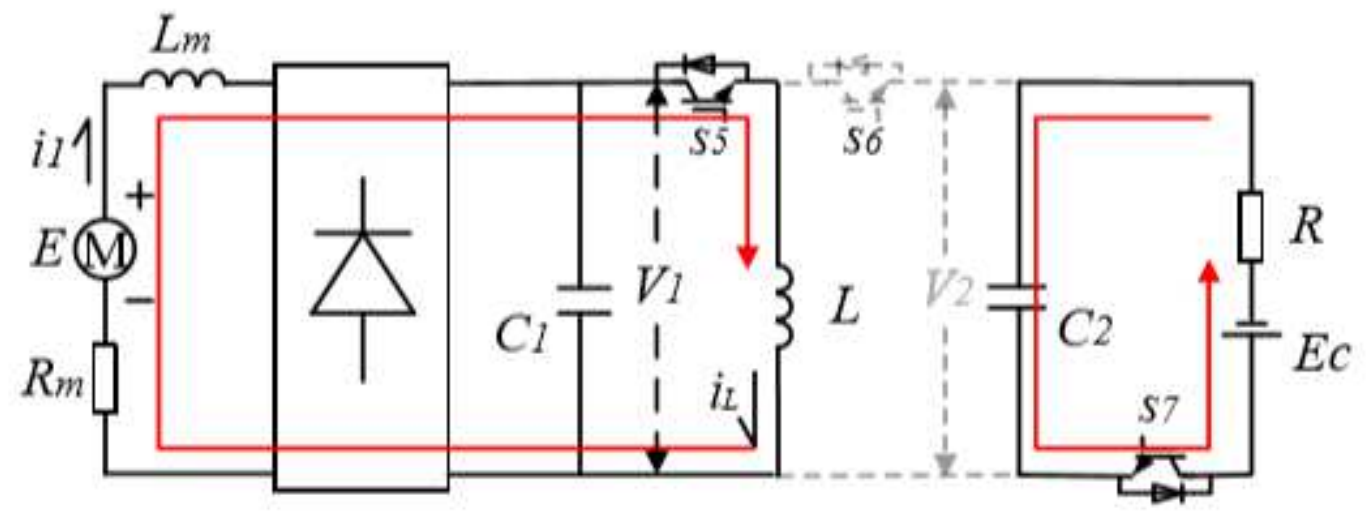

Figure 4

Conduction state of the control circuit in energy regenerative mode

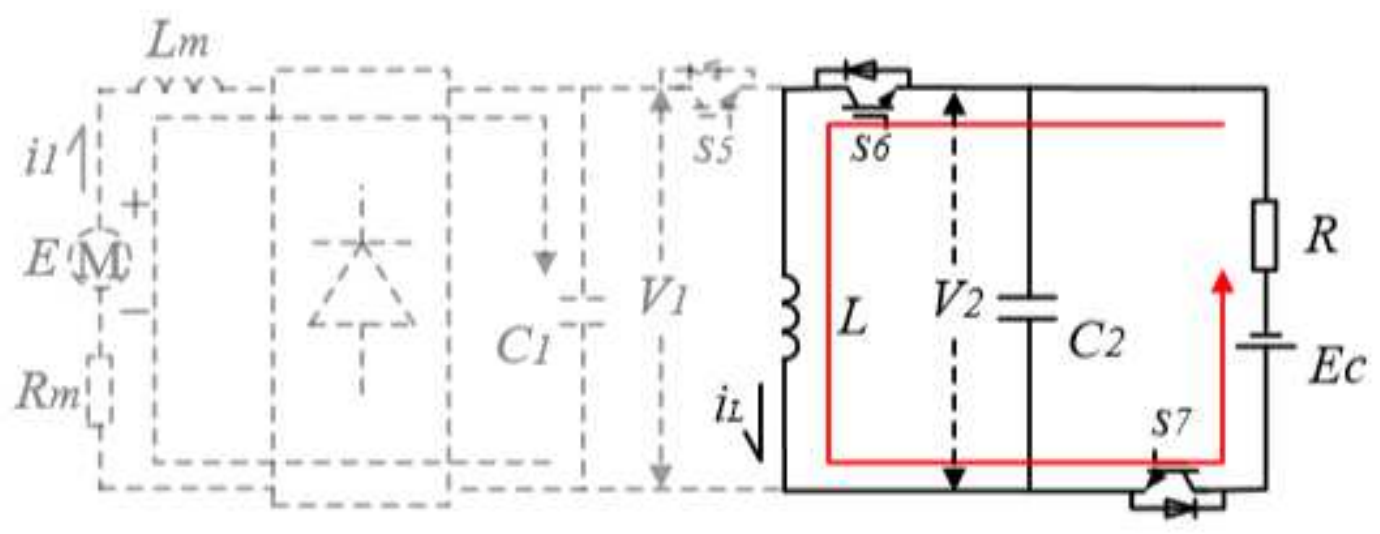

Figure 5 
Disconnected state of the control circuit in energy regenerative mode

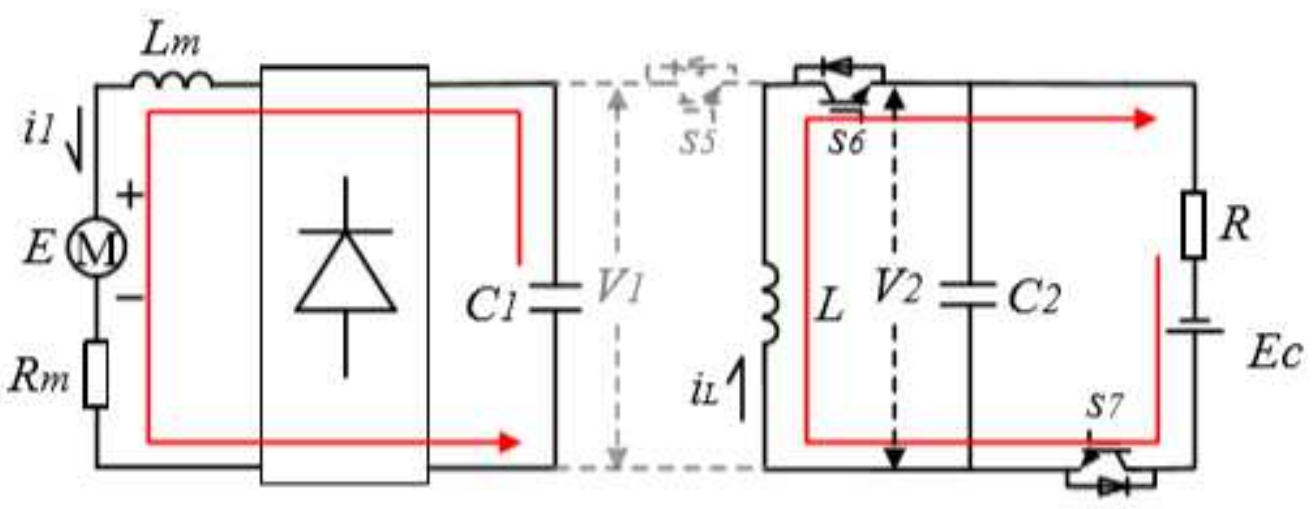

Figure 6

Conduction state of the control circuit in energy regenerative mode

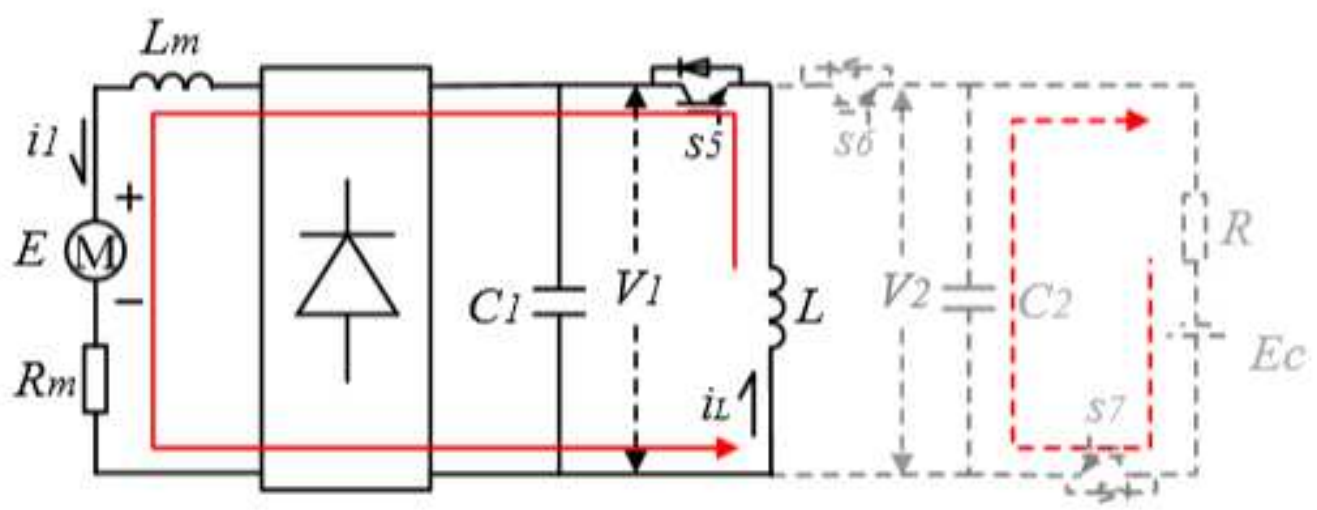

Figure 7

Conduction state of the control circuit in energy regenerative mode

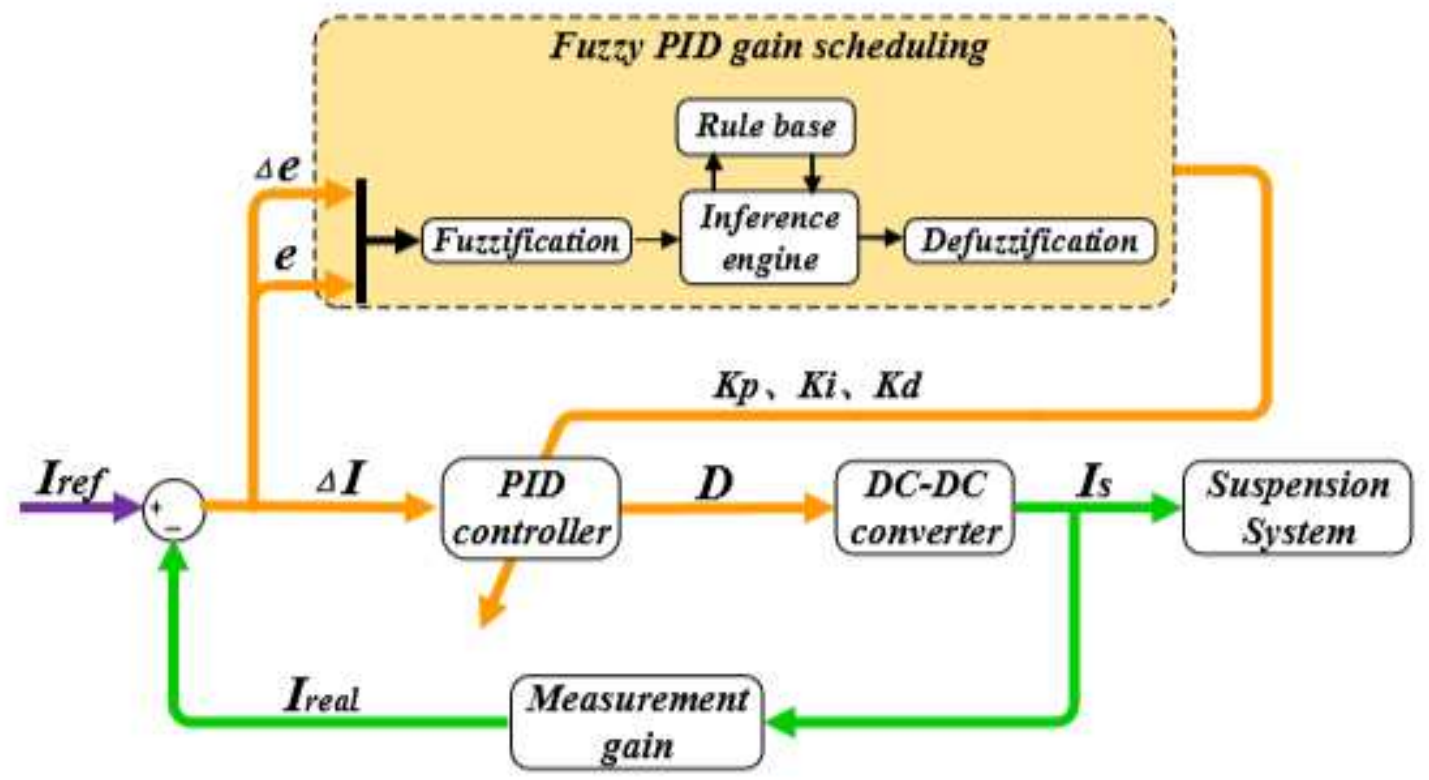


Figure 8

Fuzzy PID controller structure

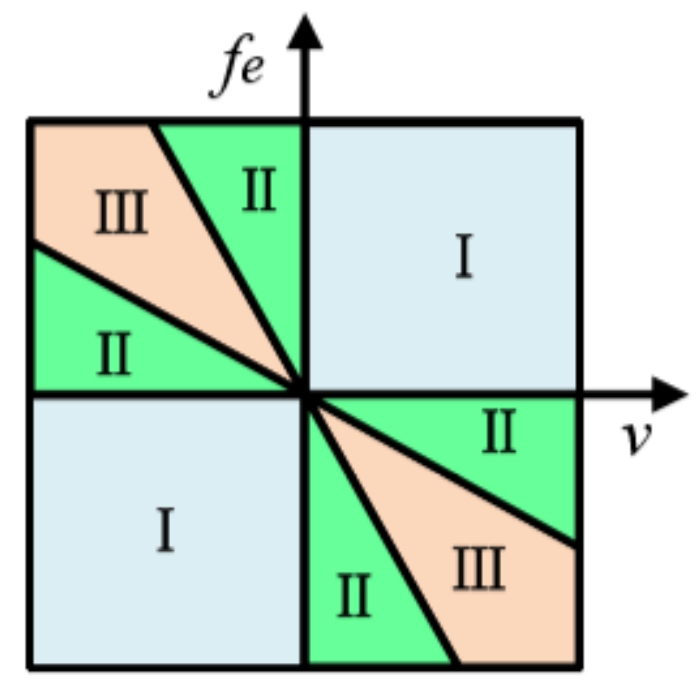

Figure 9

The operating zones of the motor

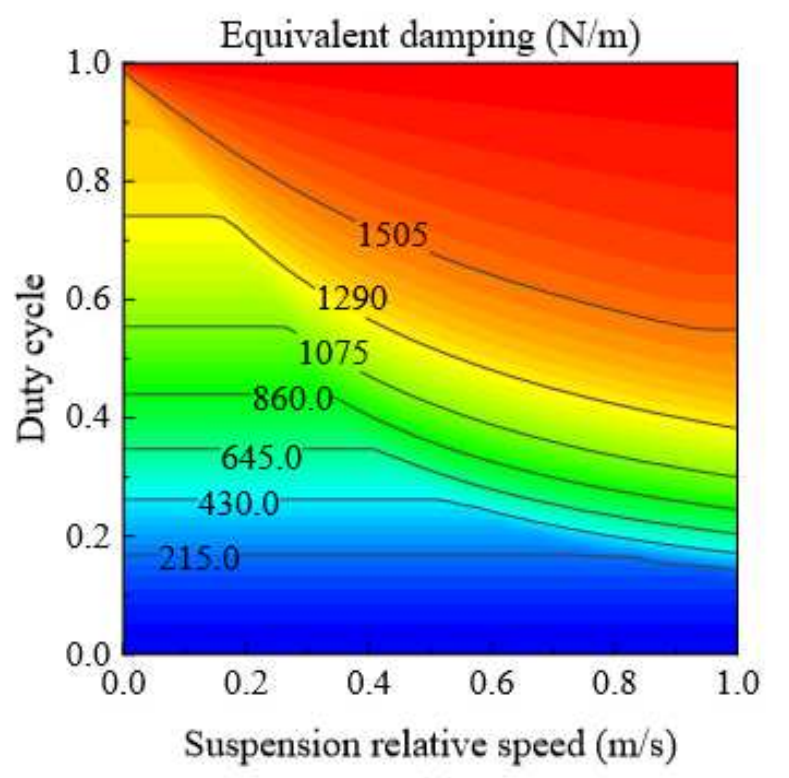

(a)

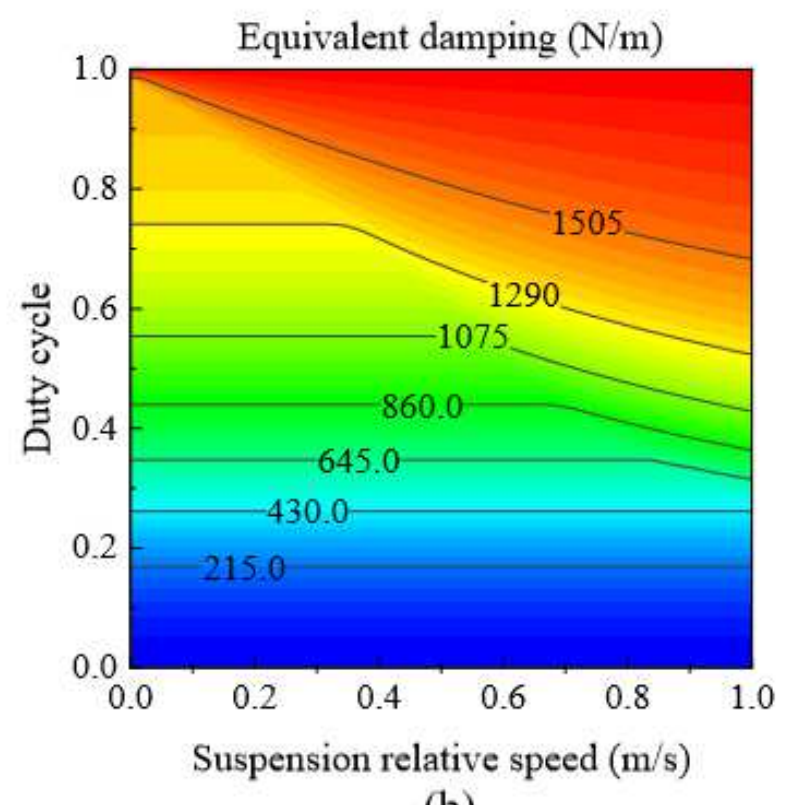

(b)

Figure 10

Equivalent damping under $12 \mathrm{~V}(\mathrm{a})$ and $24 \mathrm{~V}(\mathrm{~b})$ recovery voltage 


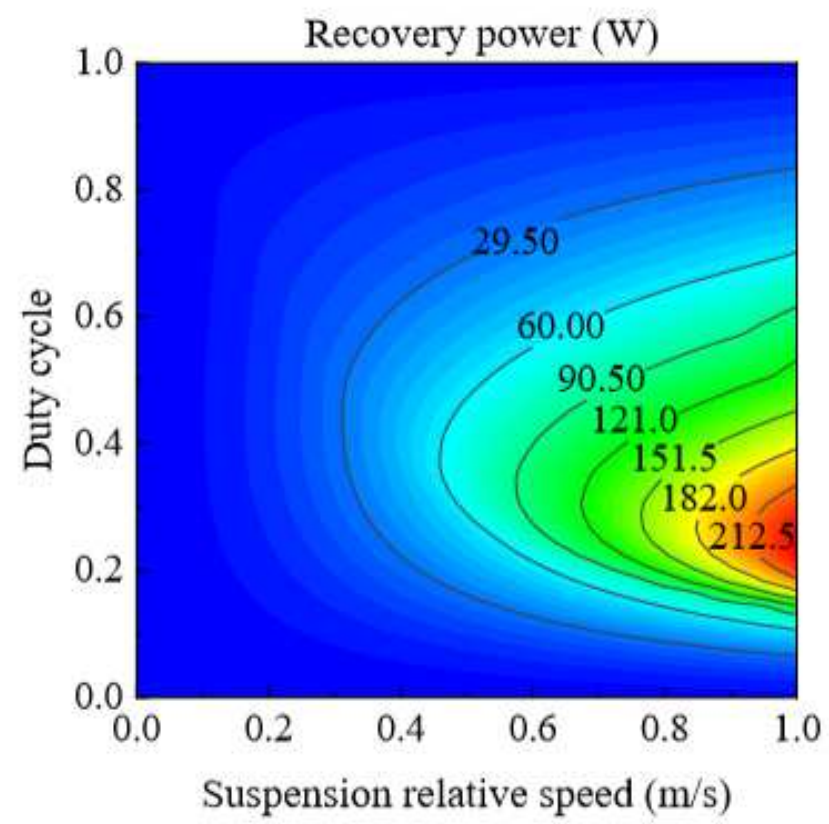

(a)

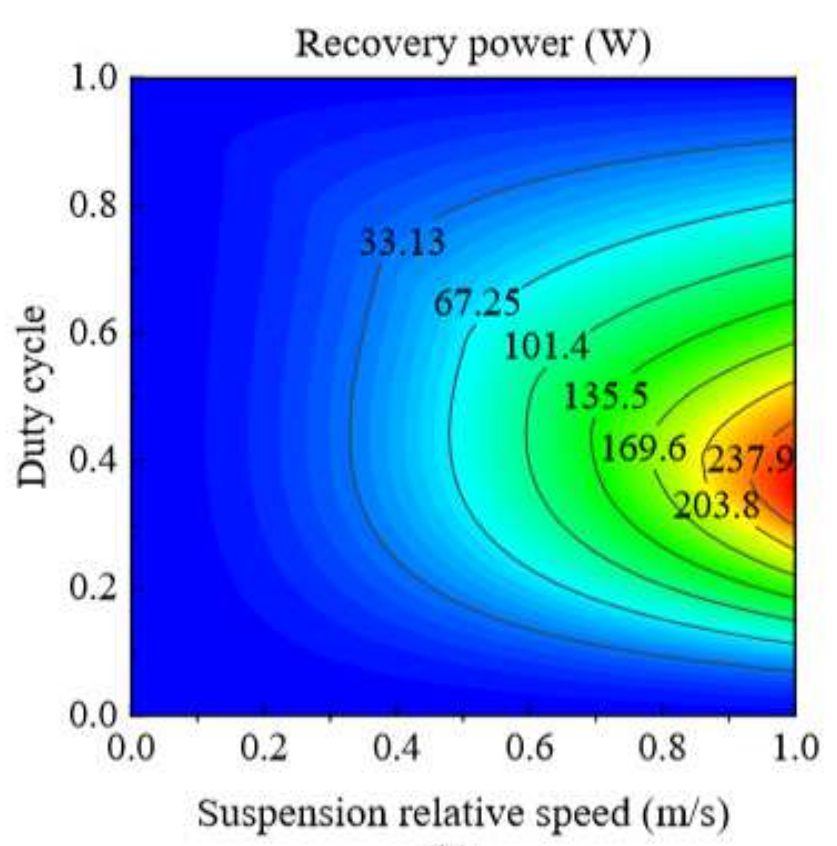

(b)

\section{Figure 11}

Recovery power under $12 \mathrm{~V}(\mathrm{a})$ and $24 \mathrm{~V}(\mathrm{~b})$ recovery voltage

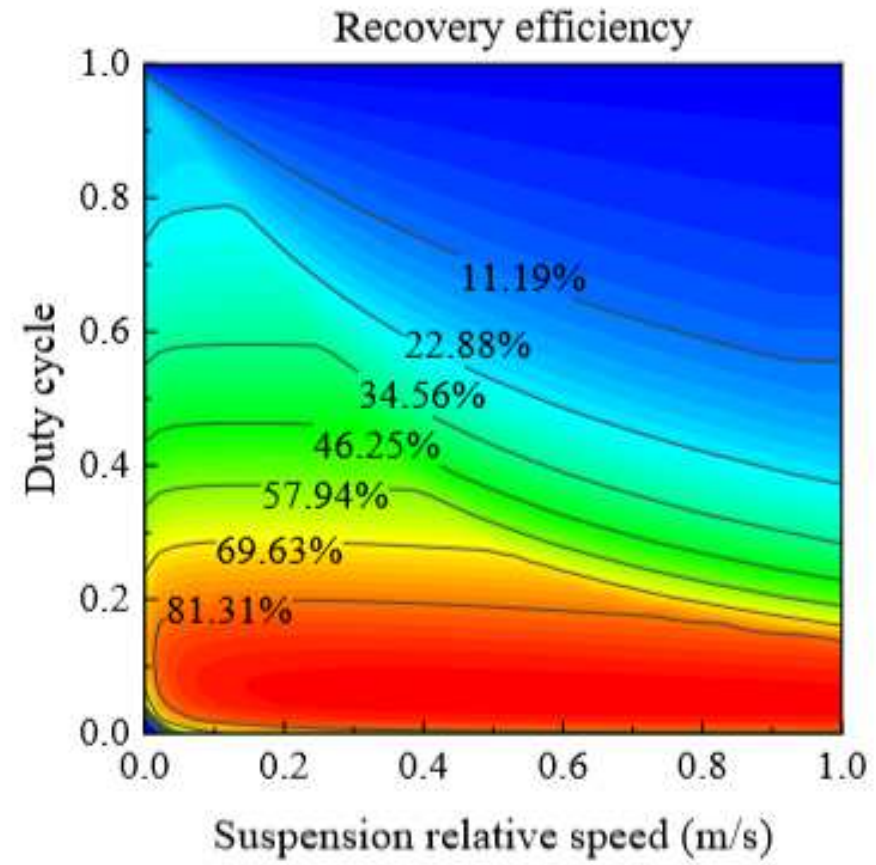

(a)

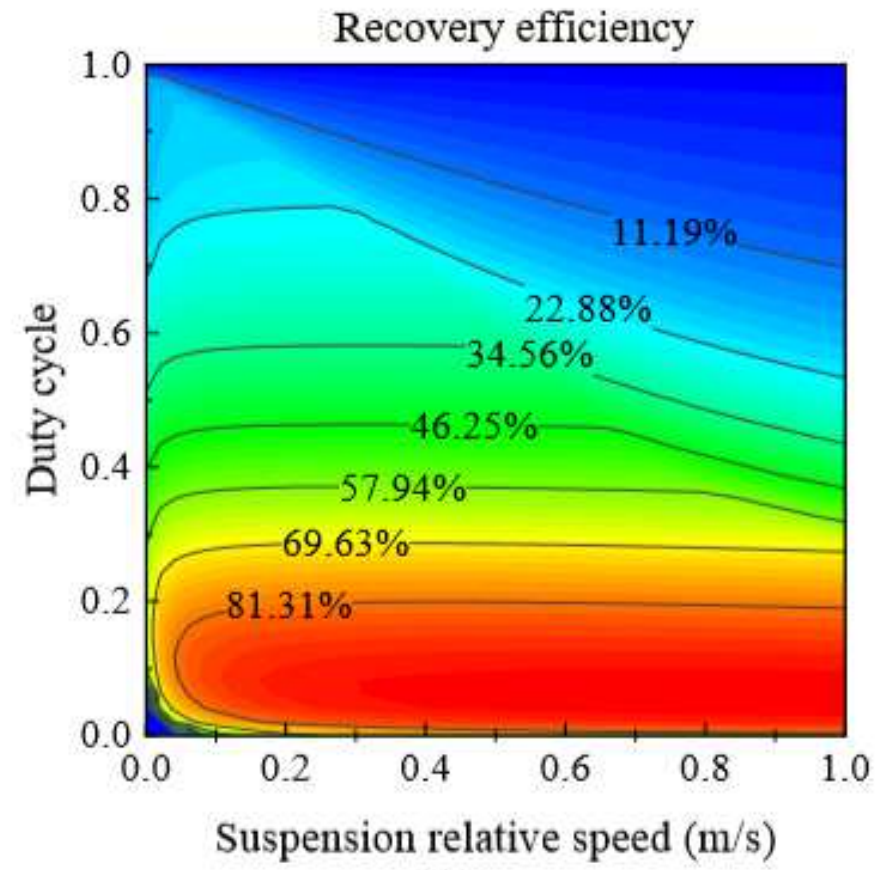

(b)

Figure 12

Recovery efficiency under $12 \mathrm{~V}(\mathrm{a})$ and $24 \mathrm{~V}(\mathrm{~b})$ recovery voltage 


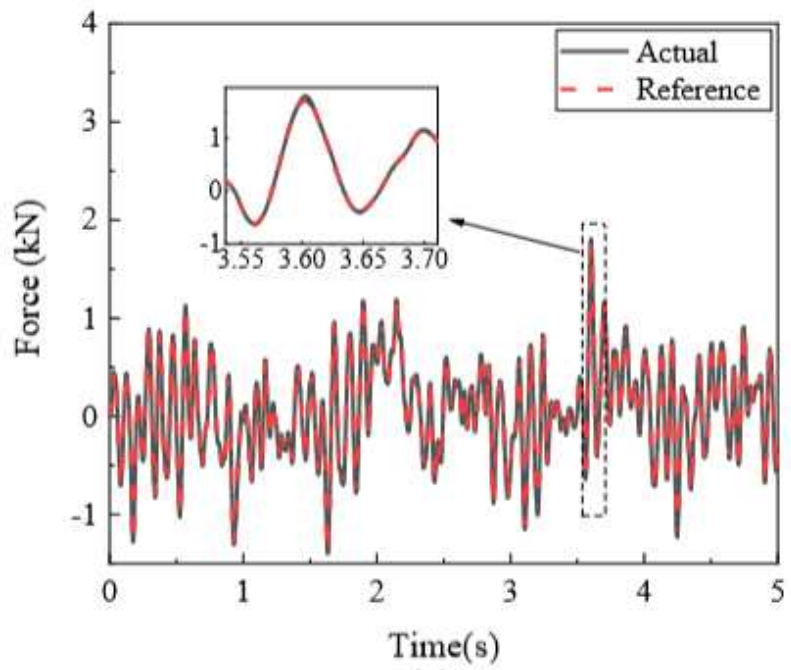

(a)

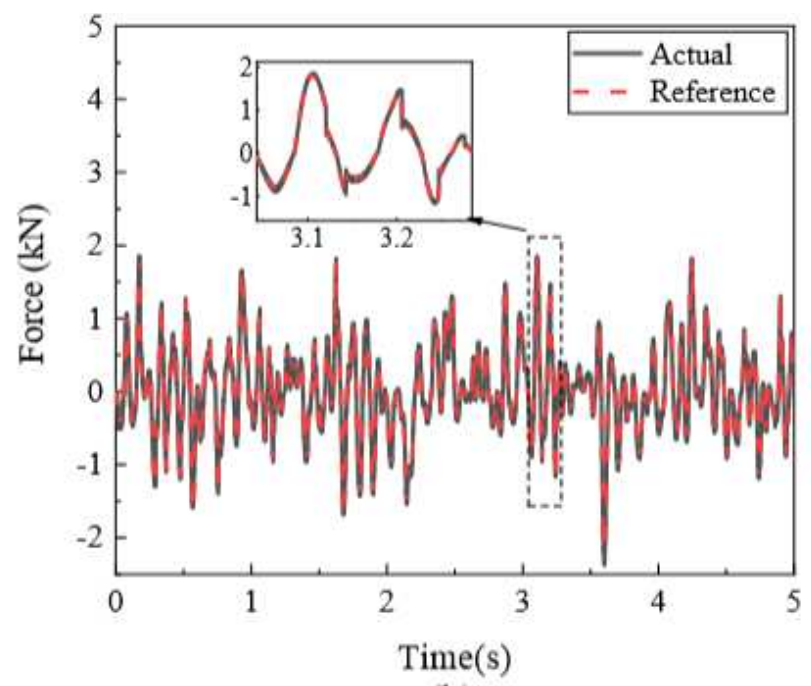

(b)

\section{Figure 13}

Comparison of ideal and actual control forece in active mode(a) and energy-regenerative mode(b) 


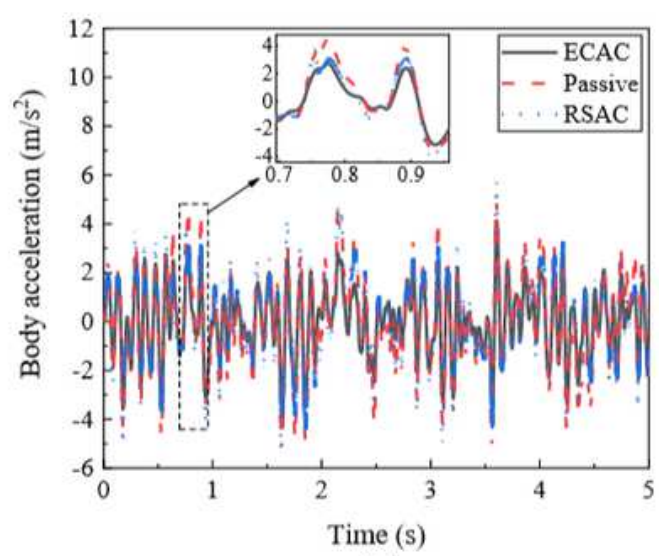

(a)

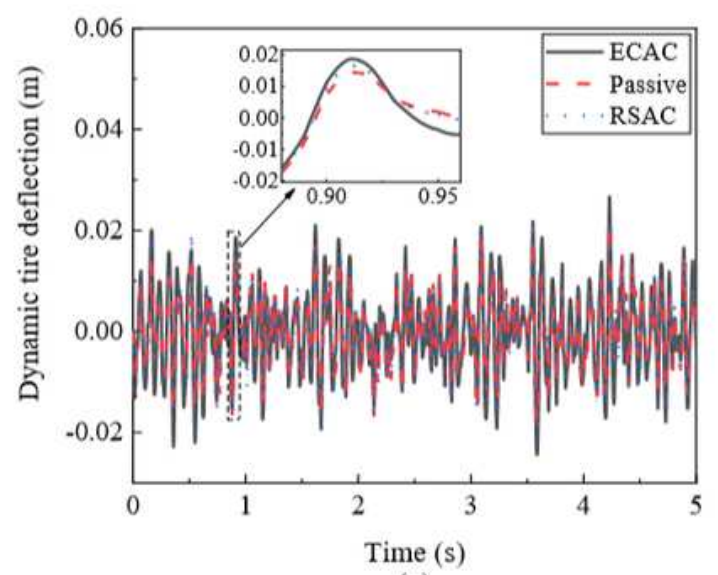

(c)

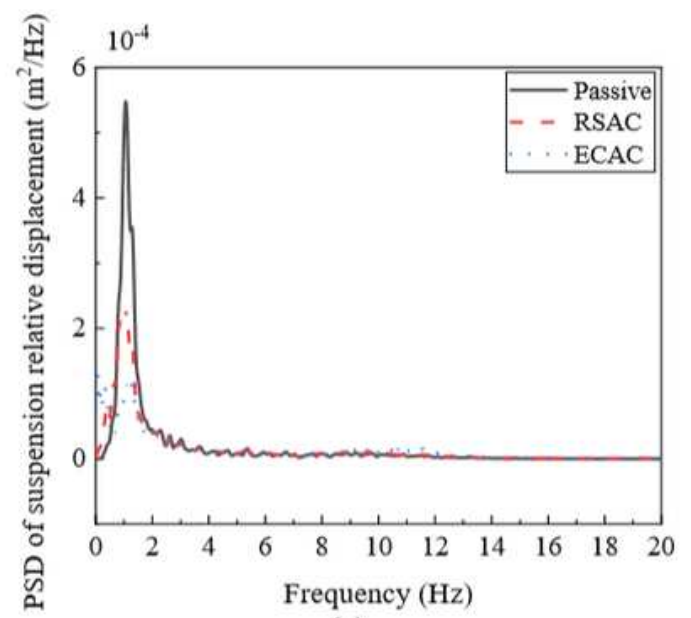

(e)

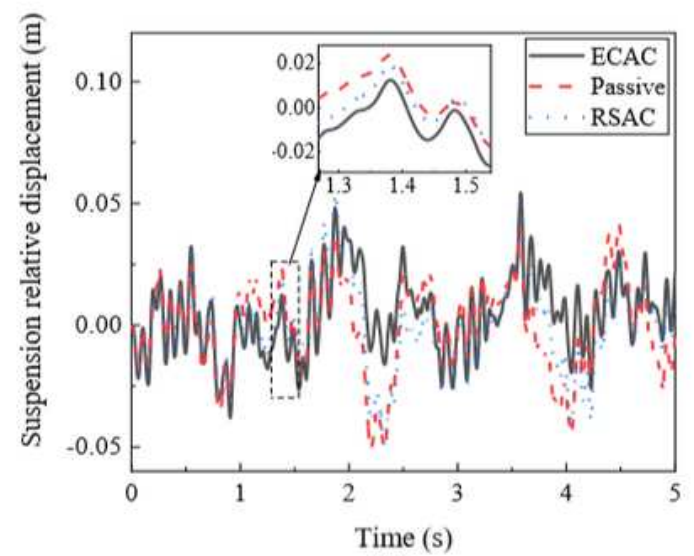

(b)

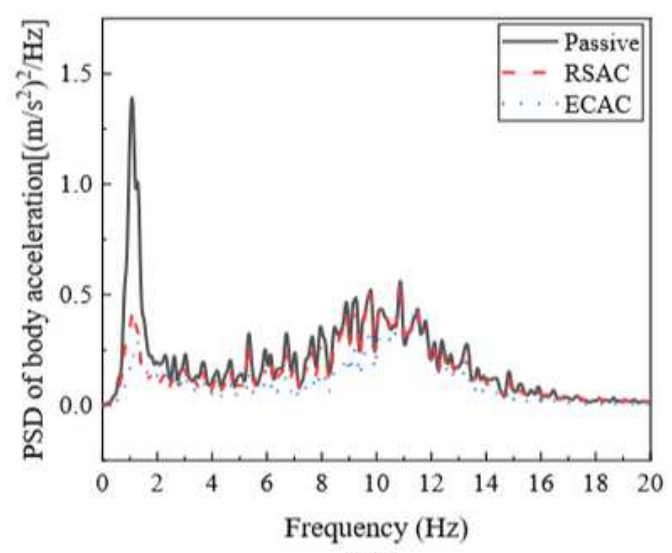

(d)

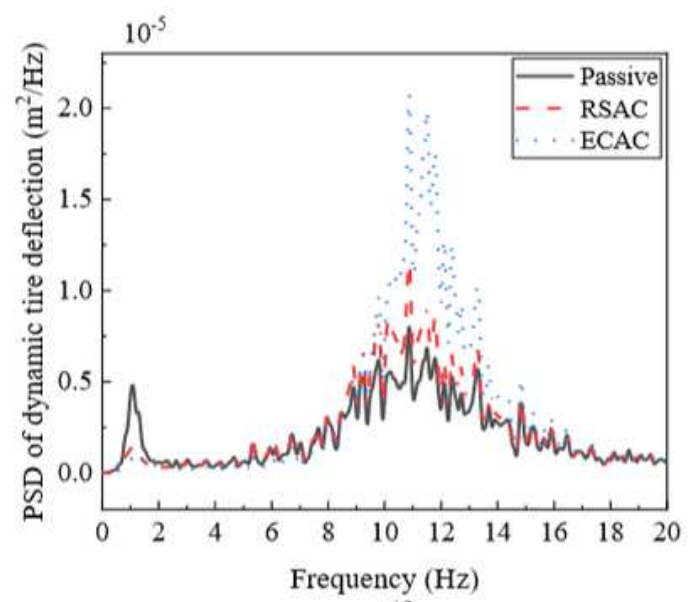

(f)

\section{Figure 14}

Comparison of dynamic performance: Body acceleration (a) time domain response and (d) frequency domain response; suspension relative displacement in (b) time domain response and (e) frequency domain; Response of dynamic tire deflection in(c) time domain and (f) frequency domain 


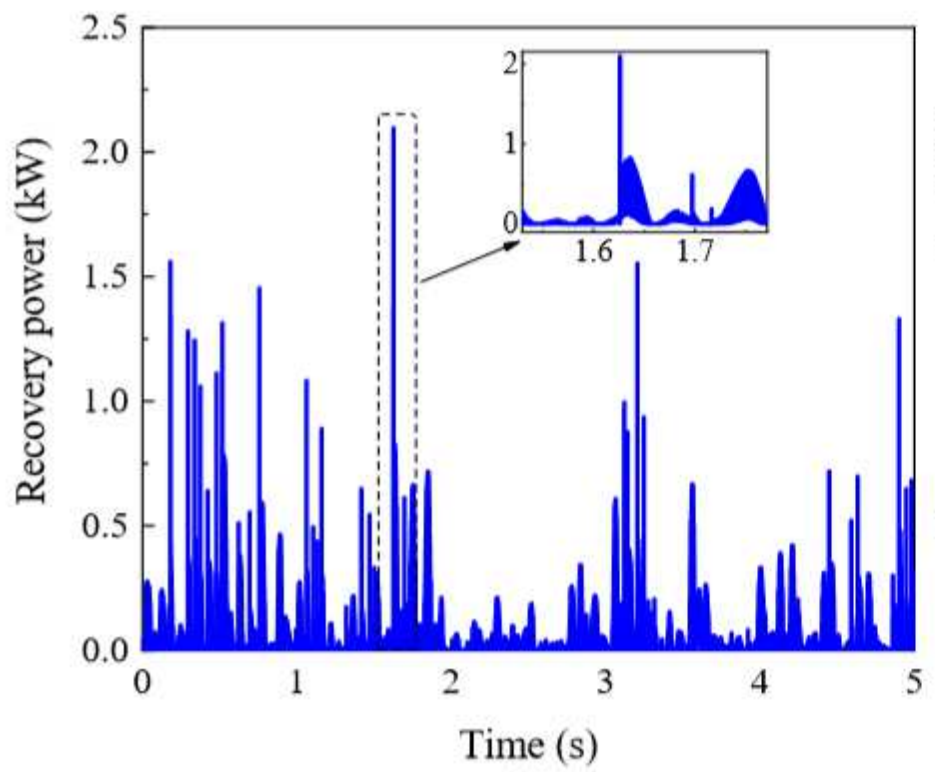

(a)

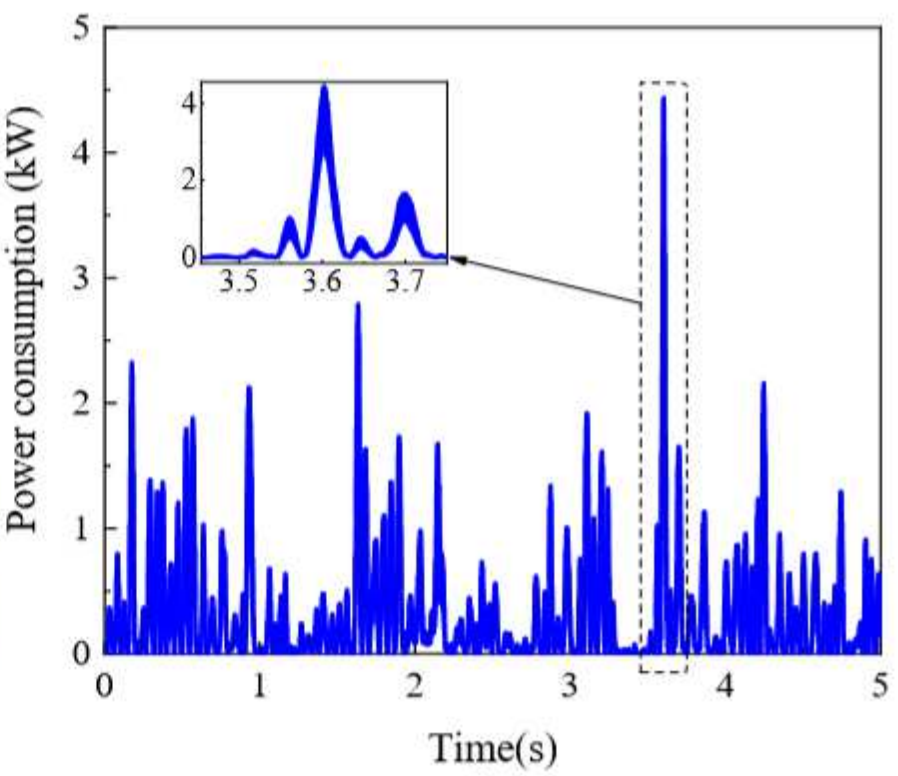

(b)

Figure 15

(a) Instantaneous recovery power in RSAC; (b)instantaneous power consumption in ECAC 